\title{
الكفاءة التنافسية ودرء الاحتكار: درس مستفاد من حظرربا الفضل
}

\author{
سيف الدين إبراهيم تاج الدين \\ كلية الاقتصباد والعلوم الاجتماعية \\ جامعة الإمام محملد بن سعود الإبلامية - الرياض - المملكة العببية السعودية
}

المستخلص. تهدف هذه الورقة إلى مناقشة وتقييم بعض الفرضيات المفسرة لطبيعة الضرر الاقتصادي المرتبط بربا الفضل من خلال منهجية الاقتصاد الإسلامي التي تدعو إلى استنباط

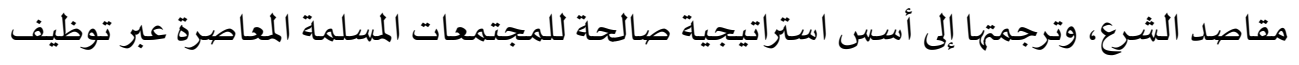

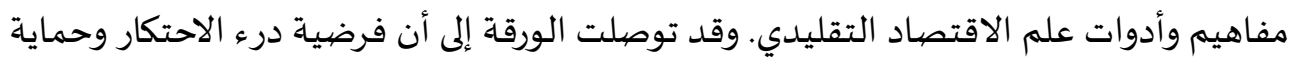
الكفاءة التنافسية في السوق هي الأقرب إلى معقول المعنى في حظر ربا الفضل بناءً على تعليل المذهب المالكي للأصناف الربوية الأربعة (التمر والبر والشعير والملح) بعلة "الطعمية المقتاتة والمدخرة"، نظرًا إلى قوة الطلب الذي يتميز به الطعام المقتات والمدخر ، وتدني مرونته السعرية في الأسـواق. ولتعزيز هذه الفرضية بالتحليل الاقتصادي مقابل بعض الفرون الفرضيات الفيات البديلة التي أشارت

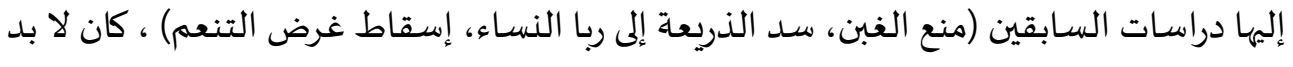
من تطوير إطار تحليلي مناسب يساعد على تقييم هذه الفرضيات ومقابلتها بفرضية البحث.

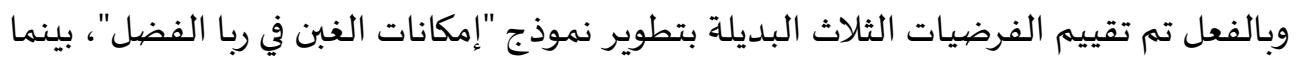

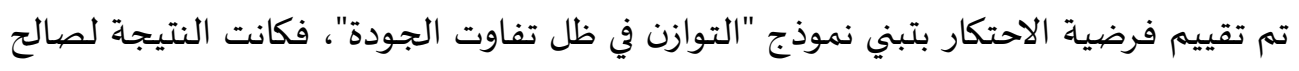

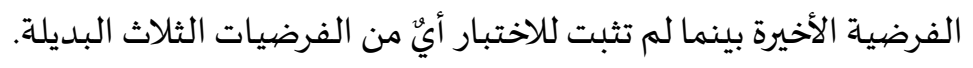

الكلمات الدَّالة: ربا الفضل، درء الاحتكار، الكفاءة التنافسية، المنهجية المقاصدية، الغبن.

$$
\text { تصنيف A11, A12, B410, B590: JEL }
$$

تصنيف B2, B5, C3, H22, I11, I16: KAUJIE 


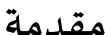

ومما يبرر استخدام أدوات وفرضيات التحليل

الاقتصادي السائد لتوضيح المقصد الشرعي (مثل رفح

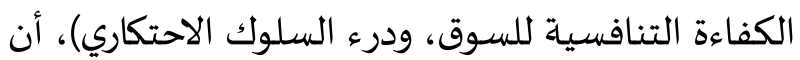

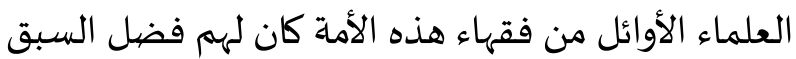
التاريخي في الفهم النظري للواقع الاقتصادي على ما هو

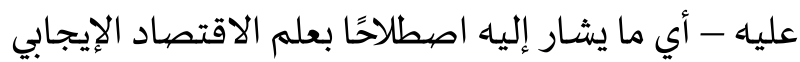
- وذلك قبل ظهور قادة الفكر (positive economics) الاقتصادي المعاصر بعدة قرون(2)، فهنالك العديد من

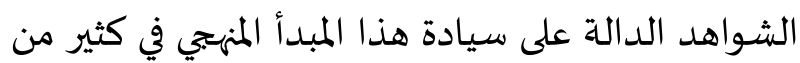
الأحكام الشرعية ذات البعد الاقتصادي أو الاجتماعي

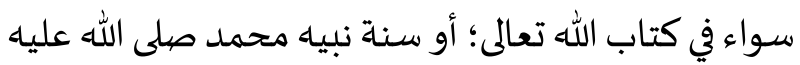
وسلم(3) . ولكن، بينما كان الدافع لفهم الاقتصاد الإيجابي بالنسبة للفقهاء الأوائل هو الحاجة للاعتراف بالأمر الوقع توطئة لإعادة توجيهه نحو مقاصد الشرع، كان الدافع

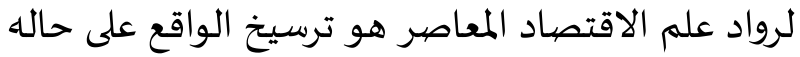
إلا في حدود معالجة قضيايا الاقتصياد الكلي مثل التوظف والنمو وعدم الاستقرار، وهذا بلا شك اختلاف جوهري.

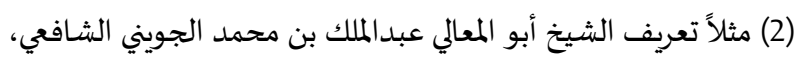

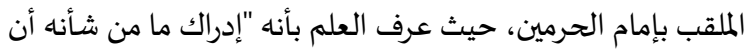

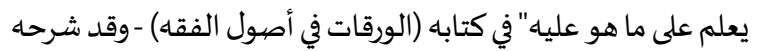

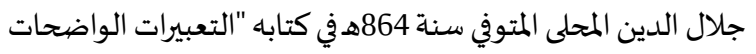

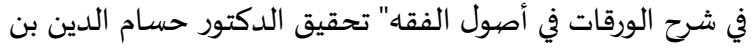

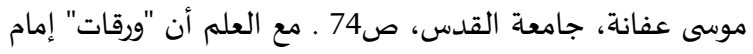

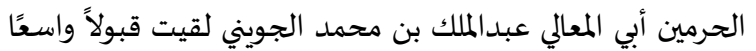

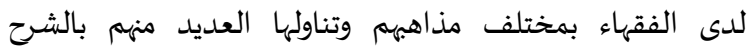

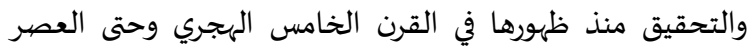

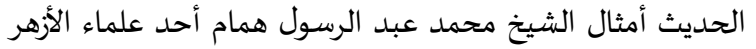

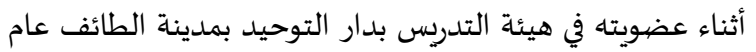
1385هـ، وقد أضاف لها الشيخ محمد بن صالح العثيمين شروحاته

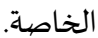
(3) بعض الأمثلة لذلك وردت في كتاب Tag el-Din, الخدة 2013
تسعى هذه الورقة لتأكيد حقيقة أن الالتفات إلى أحكام الشرع بهدف استنباط مقاصدها الاقتصادية وتنزيلها للواقع المعاصر في شكل أسس استراتيجية هو الأكثر نفعًا في عالم اليوم، وإن اقتضى الأمر توظيف أدوات وفرضيات التحليل الاقتصادي التقليدي السائد، وأن هذا الاتجاه هو الأحرى باهتمام الاقتصاديين المسلمين عوضًا عن الانخراط في

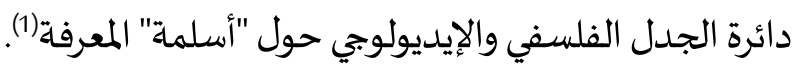
لا شك أن هذه المقولة تختزل الكثير من المضامين ذات الصلة بمسألة المنهجية العلمية للاقتصاد الإسلامي. لكن الخوض في مسألة المنهجية ليس هدفًا لهذه الورقة، وإن كانت تستند إلى ما يمكن الإشـارة إلياء بالمنهجية المقاصدية (Tag el-Din, 2013, 2017). وهي المنهجية التي لا تعتبر المباريك الموقف من قانون الندرة وفرضياته السلوكية وما ينشأ عنها من قوانين ونماذج تحليلية هي نقطة الافتراق عن علم الاقتصاد السائد (Mainstream Economics) والتوجها نحو منطلقات بديلة لعلم الاقتصاد الإسلامي، حسبما يميل إلياه دعاة "أسلمة" المعرفة، وإنما تعتبر الحرص على لى استنباط مقاصد الشرع من ذات القوانين والنماذج القائمة على قانون الندرة ، وترجمتها إلى أسس استراتيجية لمساعدة المجتمعات المسلمة المعاصرة على حل مشكلاتها الاقتصادية هو التوجاء العلمي الأكثر نفعًا في دائر أبحاث الاقتصياد الإسلامي.

(1) ظل مفهوم "أسلمة المعرفة" منذ استحداثه في ثمانينيات القرن الماضي

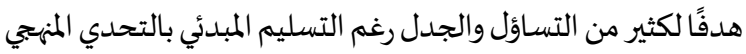
الكبير الذي يواجهه الباحث المسلم المعاصر - الفاروقي (1987م)،

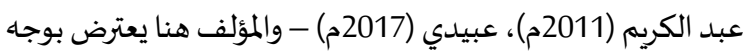

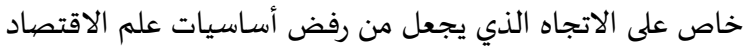

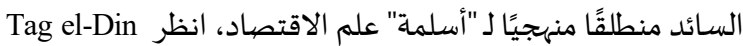

(2013, 2017). 
مساحة شـاسعة للسوق كان يعني توافر أسواق لمختلف

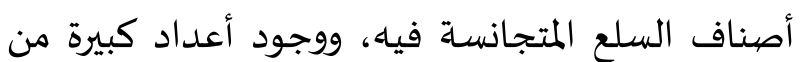
البائعين والمشترين لتلك السلع، كما يعني توافر المعلومات عنها في مكان واحد، وإتاحة حرية الدخول والخروج للبائعين السوق حيث لا يقيدهم في ذلك دفع خراج أو إتاوة لولي الأمر (يسري، 1998م، ص 7-11). ومن الواضح كذلك أن الانحراف عن الكفاءة التنافسية ينتج عن مصدرين أساسيين: (1) اكتساب أحد الأطراف قدرة احتكارية مؤثرة على سعر السوق (2) إخفاء معلومات ذات صلة بموضوع البيع (بقصد أو بغير) وذلك إلك

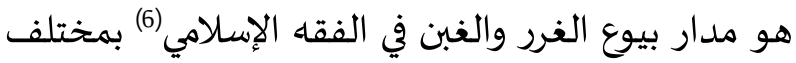
مسمياتهما وأشكالهما، ولذلك يمكن إلحاقها جميعًا صور الانحراف عن الكفاءة التنافسية، أي معايب السوق market) imperfections) أحكام السنة النبوية ذات الصلة بتنظيم الأسـواق تتسق تمامًا مع النص القرآني الذي يبيح البيع عمومًا: (أحل الله

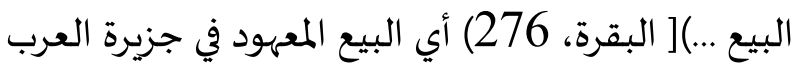
ولدى عامة البشر منذ الأذل باعتباره مبادلة السلع بالأثمان أخذًا وعطاءً - وهو بالطبع يختص هنا بالسلع الحلال ـ ولم تفعل السنة النبوية أكثر من النهي عن البيوع التي تخل من قدرة السوق على تحقيق السعر التنافسي المقبول، سواء كان ذلك بالنهي عن الغبن أو الغرر الفاحشين أو الاحتكار. لذا، فإن معايب السوق من الوجهة المقاصدية تتسع لتشمل كافة البيوع المنهي عنها، إلى جانب السلوك الاحتكاري، بينما تقتصر بحسب المصطلح Tag el-Din, 2013, ) التقليدي على صور الاحتكار فقط (pp. 169-191). ومن ثم، يمكن اعتبار رفع الكفاءة

(6) ويقصد بهما الغرر/الغبن الفاحش لأن اليسير منهما متسامح فياء خصوصًا ذا تعذر الخلاص مناه.
وعليا،، فإن حركة البحث العلمي في الاقتصاد الإسلامي تبدو أكثر حاجة إلى الأخذ بهذا المبدأ البراغماتي لمواجهة القضايا الاقتصادية التي تعاني منها المجتمعات المعاصرة، عوضًا عن مطلب التميّز النظري والأيديولوجي. 1/1 الكفاءة التنافسية ومعايب السـوق من الوجهة المقاصيدية رغم ما يبدو من غرابة مصطلح سوق المنافسـة الكاملة على فقه البيوع الموروث لكن دلالاته الاقتصادية النظرية تتسق تمامًا مع مقاصد الشرع حيث إنه يقتضي نفاذ سلطة السوق على كافة الأطراف المتعاملين فياء، بائعين ومشترين، مع عجزهم عن التأثير على السعر، فلا يملكون إلا تلقي الثمن (price-taking) والتسليم به. وخير دليل على الى اتساق هذه الظاهرة مع مقاصد الشرع إحجام النبي صلى الله عليه وسلم عن تخفيض السعر حين دعاه الصحابة دفعًا للغلاء، فكان رده صلى الله علياه وسلم: "إن الله هو المسعر "(4) تسليمًا بآلية تحديد الثمن السائدة آنذاك. وفي هذا الحديث إشـارة واضحة إلى مقاربة سوق المدينة المنورة في العهد النبوي لشروط المنافسة الكاملة بعد هجرة النبي صلى الله عليه وسلم إلى المدينة وتخصيصيه سوقًا لأهلها على مساحة شاسعة قائلاً لهه: "هذا سوقكم لا ينتقصن

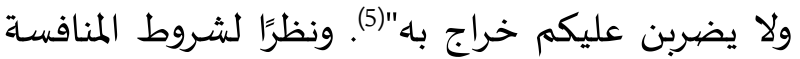
الكاملة المعهودة: (1) تلقي السعر بين أعداد كبيرة من البائعين والمشترين (2) تجانس السلعة (3) توافر المعلومات (4) حرية الدخول والخروج، فإن تخصيص

(4) الحديث: " إن الله هو المسعر القابض الباسط الرازق وإني لأرجو أن

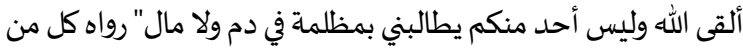

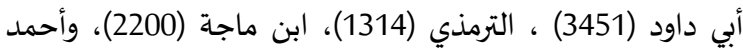

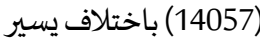
(5) رواه ابن ماجة (2233) ولهه شواهد أخرى باخير 
خلفية أسـاسية عن معايب السوق (Market imperfections) من الوجهاة الشرعية مع توضيح الفرق بين "العلة" و"الحكمة" في أصول الفقه، كمدخل أساس للنظر في العلة الكاشفة لمعقول معنى النهي عن ربا الفضل. وبناءً the على ذلك يهدف الجزء الثالث لاستنباط الفرضية مدار النظر في هذا البحث مقابل فرضيات hypothesis أخرى بديلة من دراسات السابقين، من خلال المقارنة بين علل حظر ربا الفضل الرائجة بين جمهور الفقهاء (الأحناف والمالكية والشافعية والحنابلة ) وترجيح أقربها إلى معقول المعنى من الحظر. وبما أن المقابلة النظرية بين فرضية البحث والفرضيات البديلة تحتاج إلى وضع إطار تحليلي قائم على افتراضيات (assumptions) مناسبة)(7) لتمثيل التبادل الاقتصادي لسلع مختلفة الجودة، فقد تم تخصيص الجزء الرابع لتطوير "نموذج إمكانات الغبن" بهدف تقييم قدرة الفرضيات البديلة على تمثيل معقول

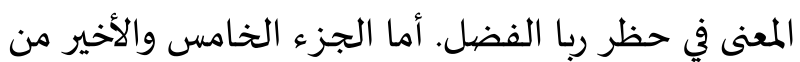
البحث فقد تم تخصيصاء لتقييم فرضية البحث من خلال "نموذج التوازن مع فرق الجودة" لكي تخلص الورقة أخيرًا إلى خاتماة موجزة بأهم النتائج والتوصيات.

2- معايب السوق وتعليل ربا الفضل

مدار البحث هو الحديث الذي رواه مسلم في صحيحها عن عبادة بن الصيامت عن النبي صلى الله عليه وسلم أنه

(7) من المعلوم أن مصطلح "الافتراض" assumption يختلف عن مصطلح

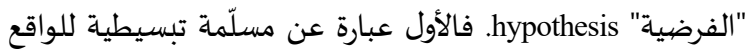

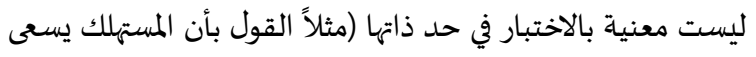
لتكبير المنفعة)، أما الثاني فهو نتيجة التحليل النموذجي المتكامل

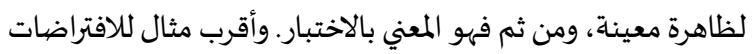

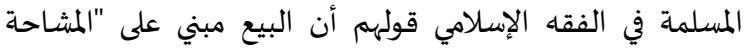

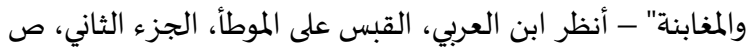

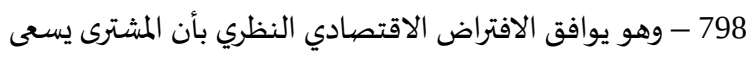
لتكبير المنفعة والبائع يسعى لتكبير الربح.
التنافسية للسوق المقصيد الشرعي الذي يجمع كلاً من درء الأطماع الاحتكارية والنهي عن بيوع الغرر/ الغبن بمختلف التفعيد صيورهما.

وبما أن البيوع المنهي عنها في الفقه الإسلامي تشمل

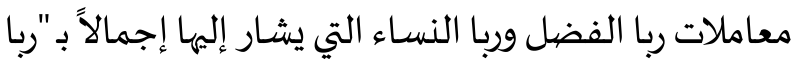

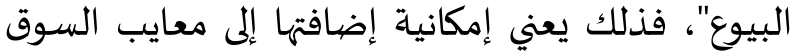

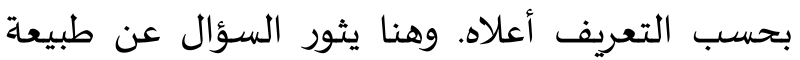
الانحراف المرتبط بهذا النوع من التبادل السلعي عن شروط الكفاءة التنافسية. لكن قد يثار التساؤل مبدئيًا

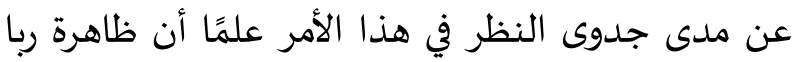
البيوع تعود إلى الزمن الغابر حينما كان نظام المقايضية

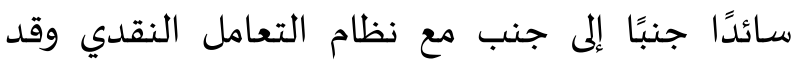

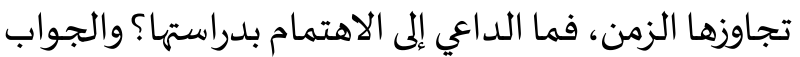

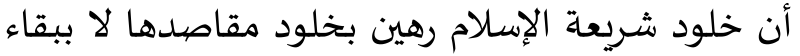
نوازلها سيما في مجال المصالح والمعاملات المالية. ومع التسليم بأن الصور الموروثة للبيوع المنهي عنها قد عفا عليها الدهر، إلا أن العبرة الاقتصادية المرتبطة بها ستظل باقية الموروهاهية

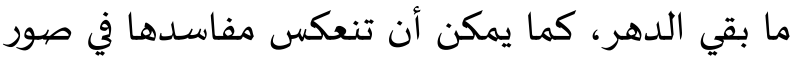
متجددة قد تخفى حقائقها. لذا، فهي في حاجة إلى التقصي النظري الدقيق. ومع لزوم الحاجة إلى النظر في طبيعة

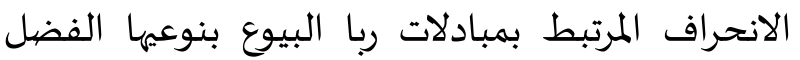

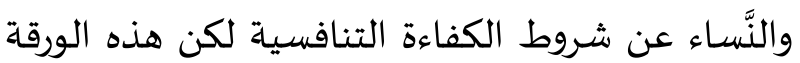

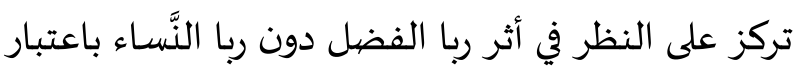
أن الأخير يحتاج إلى بحث مستقل.

2/1 خطة البحث

تشتمل خطة البحث على خمسة مباحث أساس ومباحث فرعية بما فهيا هذه المقدمة بهدف تطبيق أدوات التحليل الاقتصادي المعهودة لاستنباط الدرس المستفاد

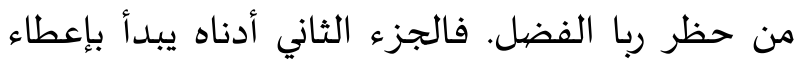


يحظر ربا النساء فقط لقوله صلى الله عليه وسلم "... فاذا اختلفت الأصناف فبيعوا كيف شئتم اذا كان يدًا بيد. ورغم اختلاف الظاهرية ونفاة القياس عن فقهاء الجمهور (الأحناف والمالكية والشـوافع والحنابلة) حول وجود علة جامعة بين هذه السلع لتقاس عليها السلع الأخرى، فلا

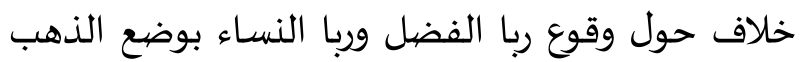
والفضة في مجموعة واحدة والسلع الأربعة الباقية (البر، القمح، التمر، الشعير والملح) في مجموعة ثانية، وبصرف النظر عن تعليلهما الفقهي من عدمه، فهذه من البداهات

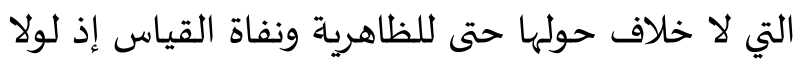
ذلك لشمل الحظر جميع بيوع الآجال. وعليه، يمكن تمثيل حكم ربا الفضل وربا النَّساء بالمصفيعة بيوعة الاجال وعلية التالية.
قال: (الذهب بالذهب والفضية بالفضية والبر بالبر والشعير بالشعير والتمر بالتمر والملح بالملح مثلاً بمثل سواءً بسواء باء باء باء يدًا بيد فإذا اختلفت الأصناف فبيعوا كيف شئتتم اذا كان يدًا بيد)(8)، إذ أنه يقتضى إخضياع التداول في الأصيناف المذكورة لحكمين أساسيين:

a بالنسبة لمبادلة الصنف بجنسـ: يكون التبادل

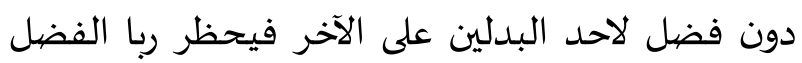
(مثلاً بمثل سواءً بسواء)، ويحظر ربا النساء ، فيكون التبادل حالاّ دون تأجيل لأحد البدلين عن الآخر (يدًا بيد) . b وبالنسبة لمبادلة الصنف بغيره: يكون التبادل حالا دون تأجيل لإحدى البدلين على الآخر (يدًا بيد)، لكن

\begin{tabular}{|c|c|c|c|c|c|c|c|}
\hline \multicolumn{8}{|c|}{ شكل (1): مصفوفة التبادل المشروع لأصيناف ربا الفضل } \\
\hline \multicolumn{4}{|c|}{ الهجموعة الثانية } & \multicolumn{2}{|c|}{ الهجموعة الأولى } & \multirow{2}{*}{\multicolumn{2}{|c|}{ بنود التبادل }} \\
\hline \multirow[t]{2}{*}{ ملح } & \multirow[t]{2}{*}{ شعير } & \multirow[t]{2}{*}{ بر } & \multirow[t]{2}{*}{ تمر } & \multirow{2}{*}{ فضة } & \multirow{2}{*}{$\begin{array}{c}\text { ذهب } \\
\text { HH } \\
\text { SS }\end{array}$} & & \\
\hline & & & & & & $\hat{\xi}$ & \multirow{2}{*}{$\begin{array}{c}\overline{3} \\
\vdots \\
\vdots \\
. \bar{y} \\
. \bar{\alpha} \\
\bar{y}\end{array}$} \\
\hline & & & & $\begin{array}{c}\mathrm{HH} \\
\mathrm{SS}\end{array}$ & $\mathrm{HH}$ & : : & \\
\hline $\mathrm{HH}$ & $\mathrm{HH}$ & $\mathrm{HH}$ & $\begin{array}{c}\mathrm{HH} \\
\text { SS }\end{array}$ & & & '3 & \multirow{4}{*}{$\begin{array}{c}\overline{3} \\
\vdots \\
\vdots \\
y \\
\overline{3} \\
3 \\
3\end{array}$} \\
\hline $\mathrm{HH}$ & $\mathrm{HH}$ & $\begin{array}{c}\mathrm{HH} \\
\mathrm{SS}\end{array}$ & $\mathrm{HH}$ & & & 2 & \\
\hline $\mathrm{HH}$ & $\begin{array}{c}\mathrm{HH} \\
\mathrm{SS}\end{array}$ & $\mathrm{HH}$ & $\mathrm{HH}$ & & & $\xi$ & \\
\hline $\begin{array}{c}\mathrm{HH} \\
\mathrm{SS}\end{array}$ & $\mathrm{HH}$ & $\mathrm{HH}$ & $\mathrm{HH}$ & & & ते & \\
\hline & & & & \multicolumn{4}{|c|}{ يداً بيد HH ، مثلًا بمثل SS ، لايوجد قيد على التبادل } \\
\hline
\end{tabular}


1/2 العلة مقابل الحكمة

باه ثم يبني عليه الأحكام فلا يكاد حكم منها يخرج عن ذلك إلا ما تعبد الله باه عباده ولم يقفهم على مصلحته ومفسداته) (المرجع السابق، ص8). كما يقول الإمام الشاطبي رحماه

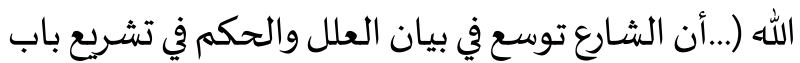

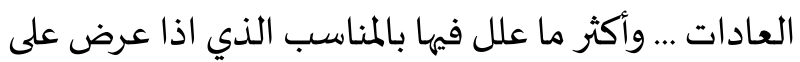

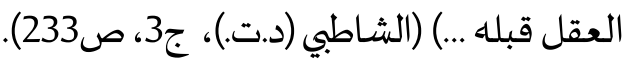
وقد درج أئمة الفقه منذ القدم على إعمال النظر في أسرار الشريعة وحكمها الخفية خاصة فيما يتعلق بدائرة جلب المصالح ودرء المفاسد ولو كان هذا التحري في معظم التهائ أحواله لا يتجاوز دافع التدبر والتفكر والتبصر في حكمة

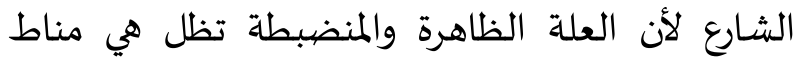

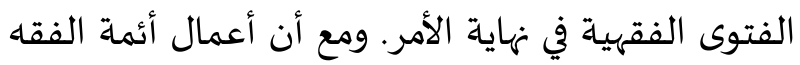

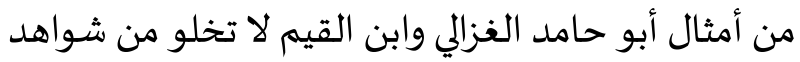

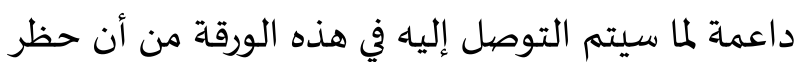
ربا البيوع إحراء نظامي للحد من مفسدة الاحتكار، فقد التد

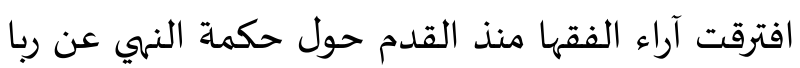
البيوع حتى قال عنها الإمام الشاطبي:

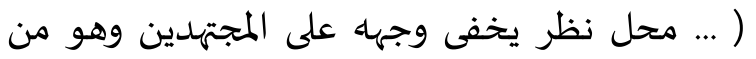
أخفى الأمور التي لم يتضح معناها إلى اليوم، فلذلك بلى بينتها

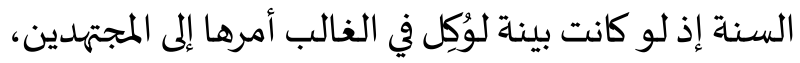
كما وُكِل الههم النظر كثير من محال الاجتهاد) (الشاطبي،

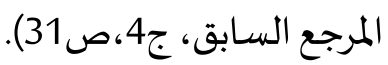

تجدر الإشارة إلى أن العبارة الأخيرة من الأصهول المعتبرة

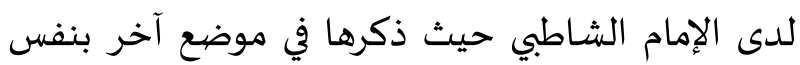
الكتاب للمقارنة بين الدليل الشرعي "المطلق" والدليل الشرعي "المقيد" (الشاطبي، المرجع السابق، ج4، ص2323).

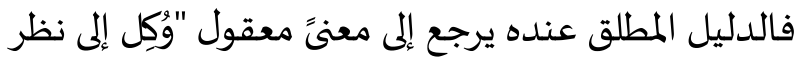
المكلف" - مثل العدل والإحسان والعفو والصبر - أما الدليل المقيد فيرجع إلى معنى تعبدي لا هيتدي إليه نظر
من الأصول المسلم بها لدى فقهاء الجمهور أن الفتوى

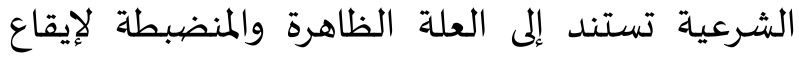

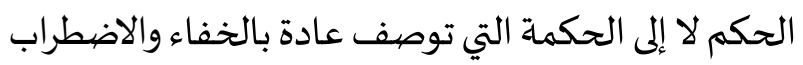

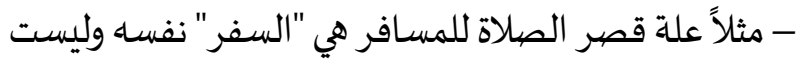
"الشعور بعناء السفر"، ولذلك يفتى بجواز القصر

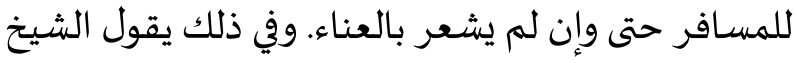
الآمدي: (إن الإجماع منعقد على صحة تعليل الأحكام بالعلل الظاهرة المنضبطة، المشتملة على احتمال الحكمم)

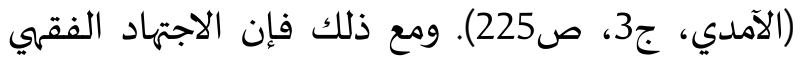
بطبعاه يحرص على أن تكون العلة الظاهرة والمنضبطة هي الماني نفسها المظنة الغالبة لوقوع حكمة الشارع أو معقول معنى المقصد الشرعي. وهو ذات النهج المتبع في فقاه القانون الوضعي، كما في وضع إشارات المرور بهدف الحفاظ على داثل حياة الأفراد وتجنب وقوع حوادث التصادم باعتبارها

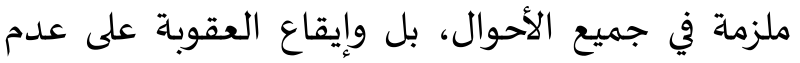
الالتزام بها حتى مع العلم أن ذلك لا يسبب خطرًا في كثير

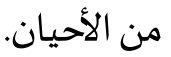
لذا، فإن التحري عن مقاصيد الشرع يستوجب البدء

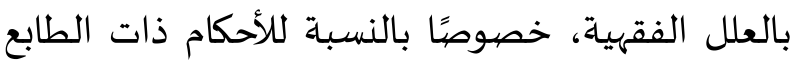
الاقتصادي، علمًا أن النظر لمعقول المعاني كان أمرًا

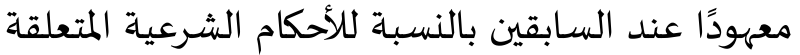

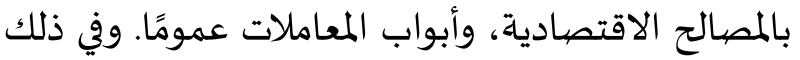
يقول الإمام العز بن عبدالسلام رحمه الله:

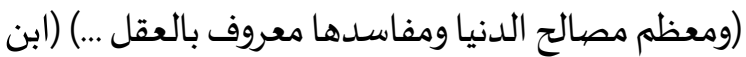
عبدالسلام (د.ت.)، ص4) ويقول في موضع آخر: (وأما مصالح الدنيا وأسباهيا ومفاسدها فمعروفة بالضرورات والتهات التجارب والعادات والظنون المعتبرات، فإن خفي شيء من ذلك ألك المعائ طلب أدلته، ومن أراد أن يعرف المناسبات والمصالح والمفاسد فليعرض ذلك على عقله بتقدير أن الشرع لم يرد المراد 
2/2 العلة الكاشفة لمعقول المعنى بما أنّ النظرة المقاصدية لربا البيوع تتطلب النفاذ إلى معقول المعنى في توزيع الأصناف الستة إلى مجموعتين: مجموعة أولى تشتمل على الذهب والفضية ومجموعة ثانية تلانية تشتمل على السلع الأربعة الأخرى، فالمدخل هو تحري العلة الفقهية الكاشفة لمعقولية هذا التوزيع. ودون تطويل حول تفصيلات الاختلاف الفقهي بين المذاهب فإن الأمر

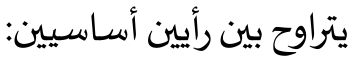
• • الرأي الأول: يأخذ بعلة "الثمنية" للذهب والفضية

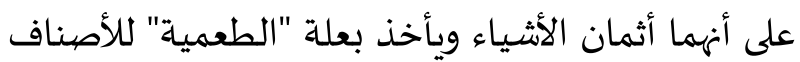

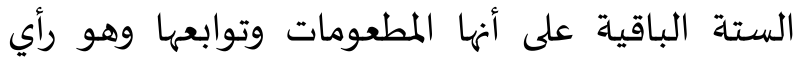

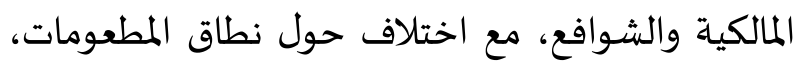
حيث يدخل فيها الشوافع كل أنواع الطعام بينما يحصرها المالكية في المطعومات المقتاتة والمدخرة فقط.

• • الرأي الثاني: يأخذ بعلة "الوزن" للذهب والفضية

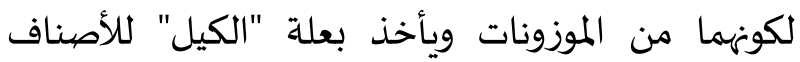

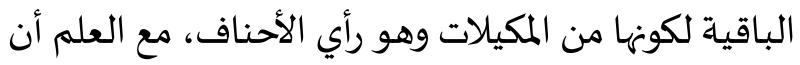
كلا الرأيين مأخوذ به لدى فقهاء الحنابلة.

يتميز الرأي الأول بتركيزه على الوصف الوظيفي للأصناف الستة الواردة في الحديث أعلاه - وظيفتي الثمن والإطعام - وهو الراجح لدى الجمهور، بينما يُركّز الرأي الثاني على الوصف الشكلي للبنود، ولذلك يُعاب عليه إدخال بعض الموزونات التي يجوز فيها السلم (مثل الجبس لونس والجير) ضمن مجموعة الذهب والفضاة مما يوقعها في

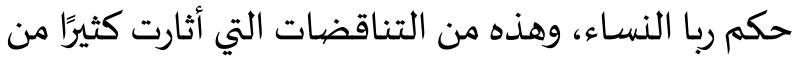

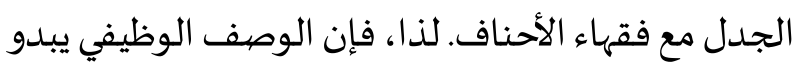

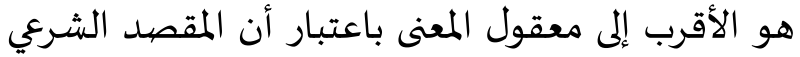
من تحريم ربا الفضل والنساء الحفاظ على وظائف الأثمان

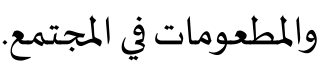

المكلف فيما لو وُكِل إلى نظره. وبذلك يبدو الإمام الشاطبي أشد تحفظًا من الإمام العز بن عبدالسلام في السماح

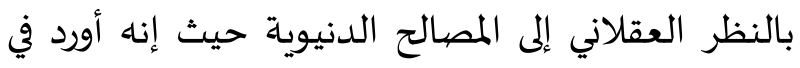

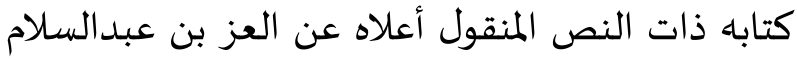
بعبارة: "يقول بعض الناس... " معرضًا عن ذكر قائله

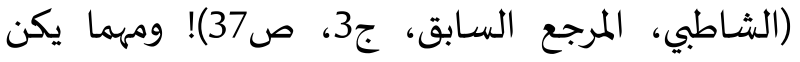
الحال، فقد حقّ لفقهاء الجمهور منذ القداق إلى إيلاء "الحكمة" دورًا ثانويًا لأن الفتوى لا تستند إلهيها أصلاً،

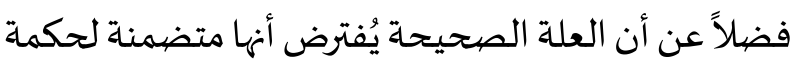

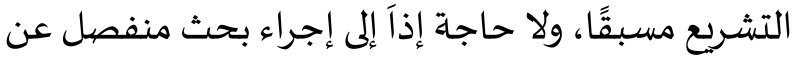
الحكمة أو حتى الاشتغال بها لولا غرض التحا التدبر والتبصر. وعليه، فإن الاشتغال بالفتوى ليس من شأن علم الاقتصاد الإسلامي وإنما من شأنه النظر في الحقائق

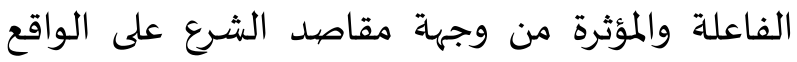

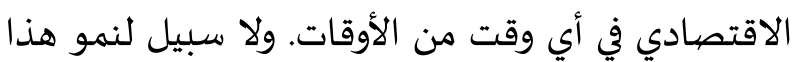
العلم وازدهاره إلا بتحري مظان الحِكَمة الاقتصادية المرتبطة بالشرائع مهما غلب عليها الخفاء والتعقيد التحريد واستوجبت قدرًا كبيرًا من الرصانة العلمياة، فذلك هو العياء التحدي الماثل في طريق استلهام الحلول والسياسات الكفيلة بتوجيه النشاط الاقتصادي نحو المقاصد

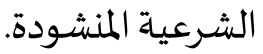

وعلى وجه الخصوص، لا يخرج النظر لطبيعة المفسدة الاقتصادية المرتبطة بربا البيوع (بشقيه الفضل والنساء)

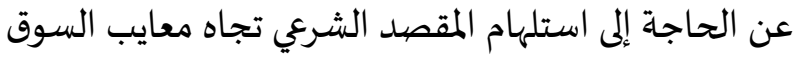
كما تم تعريفها آنفًا. والمدخل (Market Imperfections) التحليلي المتبع في هذه الورقة يقوم على تكييف نقطة الافتراق الأساس بين البيع الشرعي الحال والتبادل المحظور

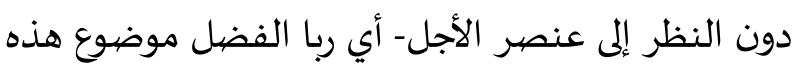

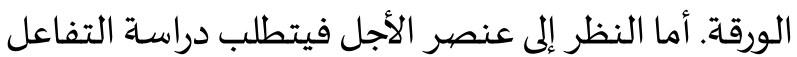
بين ربا الفضل وربا النساء وهو خارج نطاق هذه الورقة. 


\section{3 - فرضية البحث والفرضيات البديلة}

ج2، ص137)، وفي موضع آخر يتنبه ابن القيم إلى المقصد الشرعي في تخصيص المطعومات بالأقوات قائلاً (وأما الأصناف الأبربعة فحاجة الناس إلهها أعظم من حاجتهم إلى الى

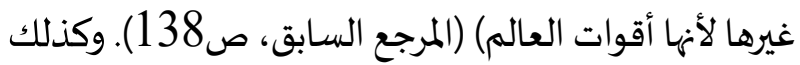

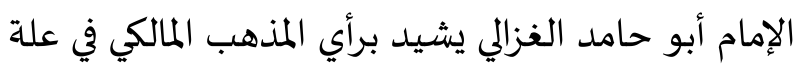
الطعمية رغم أنه من أعلام المذهب الشافعي، قائلاً (...

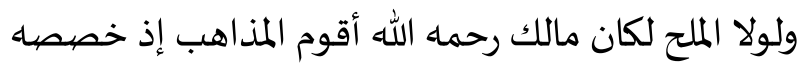

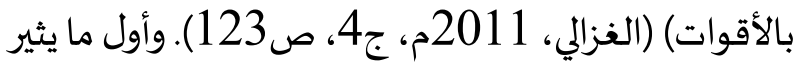
الاهتمام نظريًا في شأن الأقوات المدخرة أنها تمتاز بخصلتين رئيستين: (1) شدة الحاجة إلهها، ومن ثم استمرار قوة الطلب

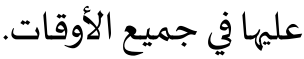

(2) تدني المرونة السعرية للطلب عليها (أي قلة حساسية

$$
\text { الطلب لارتفاع السعر). }
$$

وفي الحقيقة، لا يحتاج الطمع الاحتكاري إلى أكثر من

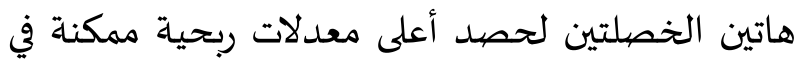
سوق السلع. زد على ذلك، فإن خاصية قوة الطلب وقلة المرونة السعرية تنطبق على الصنف الأدنى جودة لأنه قوت الكان

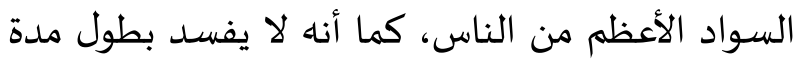

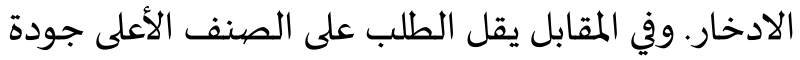
لكونه قوت الطبقة المنعمة في المجتمع وترتفع مرونته السعرية، ليس فقط لتوفر البديل الأرخص والأدنى جودة، وإنما كذلك لتلاشي صفة الجودة مع طول فترة الادخار. ومن بين الفقهاء المعاصرين الذين صرحوا بحكمة درء السلوك الاحتكاري للمطعومات المقتاتة في ربا الفضل الإمام محمد أبو زهرة رحمه الله بقوله: (أما المطعومات المات المات الفهات القابلة للادخار فإن تحريم المعاوضة بأجناسها مع الفضل،
بناءً على العرض السابق سيتم استنباط فرضية

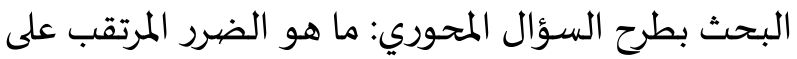

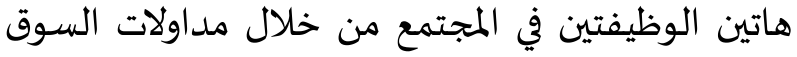

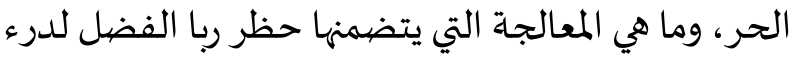
ذلك الضرر؟ لا شك أن الإجابة على هذا السؤال تتطلب النظر في وظيفتي الثمنية والطعمية، كلاً على حدة، بهدف الوقوف على طبيعة الضرر الذي يمكن أن تتعرض له كلاً

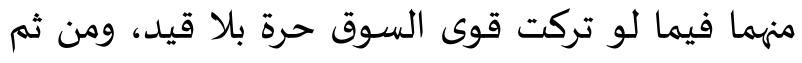
التعرف على طبيعة المعالجة التي يقدمها حظر ربا الفضل

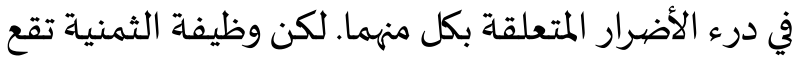
خارج نطاق هذا البحث لارتباطها بالوظيفة النقدية

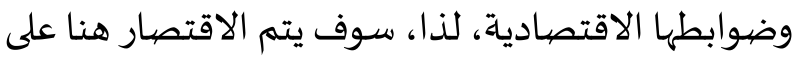
الوظيفة الثانية - أي وظيفة الطعمية - لصياغة فرضياة البحث حول حقيقة الضرر المقصود بالدرء. ومن ثم ينبغي المفاضلة بين التعليل الشافعي الذي يُدخل كل أنواع الطعام من أقوات وفواكه وثمار وأدوية

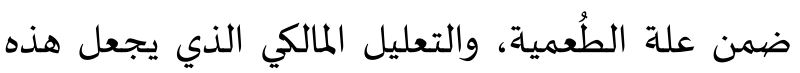
العلة قاصرة على المطعومات المدخرة والمقتاتة وما يصلحها. هذا مع ملاحظة تميز التعليل المالكي بأنه لا

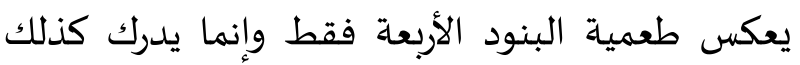

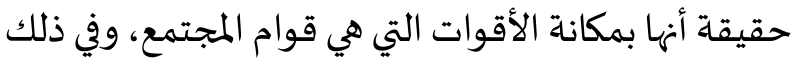
تنويا بالمقصد الشرعي من إعطاء حماية خاصة لهذها الأقوات دون غيرها من المطعومات. وليس مستغربًا ميل كثير من الفقهاء الأوائل إلى تقييد علة الطعمية بالمطعومات المعات المقتاتة دون غيرها من الأصناف. مثل الإمام ابن القيم

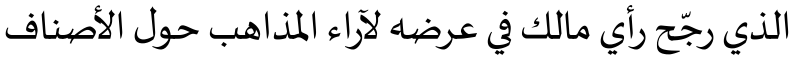

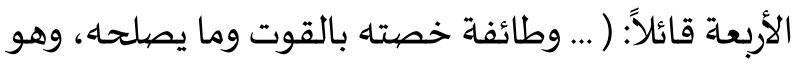
قول مالك، وهو أرجح هذه الأقوال) (ابن القيم، 1977م، 
القطعة المنقوشـة نقشًا بديعًا من الذهب تساوي زنتها مرتين وفي ذلك غبن بالناس ..)، (الجزيري، 2003م، ج2، ص247). وسوف يشار إليه هنا اختصيارًا بحجية الغبن. ثانيًا: فرضية سد الذربعة لربا النساء: وهي القول بأن ربا الفضل لا يحتوي على مفسدة في حد ذاته، كونه قرين بالربح "المعجل"، وإنما جرى تحريمه لأنه ذربعة قرببة جدًا للوقوع في مفسدة الربح "المؤخر" في ربا النساء وهي المفسدة الحقيقية المستحقة للدرء. وذلك ما ذهب إليه الإمام ابن القيم بقوله في شأن الأثمان: (وأما ربا الفضل فتحريماء من باب سـد الذرائع،

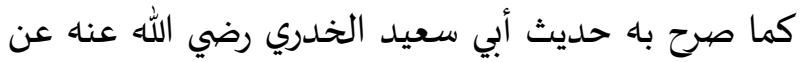
النبي صلى الله عليه وسله: لا تبيعوا الدرهم بالدرهمين فإني أخاف عليكم الرماء. والرماء هو الربا، فمنعهم من ربا الفضل لما يخافه عليهم من ربا النسيئة. وذلك أههم إذا باعوا درهمًا بدرهمين، ولا يفعل هذا إلا للتفاوت بين النوعين إما في السكة وإما في الخفة، تدرجوا في الرتح المعجل فيه إلى الربح المؤخر وهو عين ربا النسيئة، وهذه ذريعة قريبة جدًا. فمن حكمة الشارع أن سد عليهم هذه الذربعة ومنعهم من بيع درهم بلدرهمين نقدًا ونسيئة ..). وكذلك قوله في شأن المطعومات: (... وسر ذلك، والله أعلم، أنها لو جاز بيع بعضها بعضًا نساءًا لم يفعل ذلك أحد إلا إذا رتح، وحينئذٍ تسمح نفسـاء ببيعها حالة لطمعاه في الربح فيعز الطعام على المحتاج ويشتد ضرره.... ففطموا من النساء ثم فطموا من بيعها متفاضلاً يدًا بيد، إذ تجرهم حلاوة الربح وظفر الكسب إلى التجارة فيها نساءًا، وهو عين

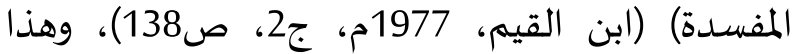
التحليل الفقهي بدوره يدعو إلى النظر حول كيفياة تحقق

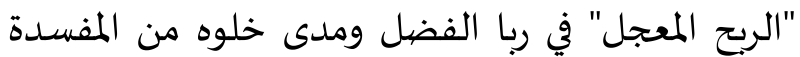
مقابل "الربح المؤخر" في ربا النساء.
الحكمة فياه واضحة، وهي منع احتكارها لمن يملكونها ...) (أبو زهرة، 1999م، ص 57)، وهذا يتسق مع تصنيف ربا البيوع بشقياء الفضل والنساء ضمن معايب السوق المخلة بالكفاءة التنافسية (Tag el-Din, 2013, pp 169-191). إذًا، ذلك هو الأسـاس النظري الذي تستند إلياء فرضية درء الاحتكار من حظر ربا الفضل في المطعومات، لكن التحقق العلمي من هذه الفرضية يتطلب مقابلتها بفرضيات أخرى عن المقصد الشرعي، ومن ثم الترجيح فيما ينها جميعًا، ولذلك تبدو الحاجة إلى تطوير إطار تحليلي مناسب يساعد على إجراء هذا الترجيح كما سيتبين في المبحث التالي. 1/3 الفرضيات البديلة والإطار التحليلي المناسب يبدو من المبحث السابق أن فرضية درء الاحتكار جد المديد قرببة لتفسير الضرر المقصود بالدرء في المطعومات لكن هنالك فرضيات أخرى بديلة أشار إليها الأسبقون حول

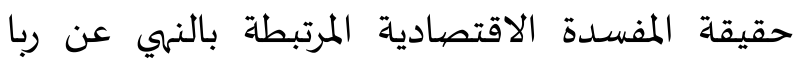
الفضل تتلخص في الاتجاهات التالية:

أولاً: فرضية الغرر المفضي إلى الغبن (أوفرضية الغبن اختصهارا): وهي القول بأن مقايضية نفس السلعة مختلفة الجودة (تمرًا بتمر مثلاً) بين صاحب الصنف الجيد وصاحب الصنف الرديء تغري الطرف الأكثر خبرة باستغلال جهل الطرف الأقل خبرة والمبالغة في تحسين نوعية صنفه حتى يقع الغبن على الطرف الآخر ـ وقد أورد الإمام ابن رشد القرطبي رايًا لبعض المالكية في أن حكمة النهي عن ربا الفضل هي (أن لا يخبن الناس بعضهم بعضيًا وأن تحفظ أموالهه) (ابن رشد، 1995م، ج2، ص131) وهذا ما ذهب إليه الشيخ عبدالرحمن الجزيري بقوله (وإنما حرم ذلك لما عساه أن يوجد من التحايل والتلبيس على بعض ضعاف العقول فيزين لهه بعض الدهاة أن هذا الأردب من القمح مثلاً يساوي ثلاثة لجودته، أو أن هذه 
b توفر المعلومات (الكفاءة المعلوماتية): بمعنى أن

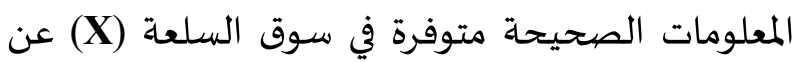
صنفيها الجيد (H) والرديء (L) وأن سعريهما محددان بواسطة قانوني العرض والطلب ومعلوماتهما متاحة لكل الأطراف المتعاملين بلا تكلفة.

وبما أن عملية الترجيح بين الفرضيات المذكورة أعلاه تتطلب بناء نماذج مناسبة ضمن هذا الإطار التحليلي، فقد تم بناء نموذجين أساسيين لهذا الغرض: النموذج الأول ويشار إليه هنا بنموذج "إمكانات الغبن في ربا الفضل لهيل

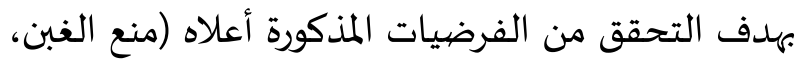

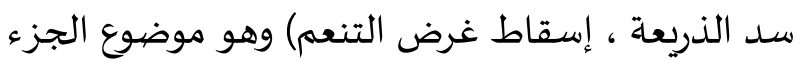

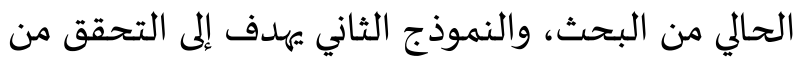
فرضية درء الاحتكار وهو موضوع الجزء اللاحق من البحث.

وقد تم تمثيل نموذج "إمكانات الغبن" في الشكل التوضيحي رقم (2) الذي يرتكز على المقارنة بين معدلين أسـاسيين: (1)معدل "فضل الجودة في السوق" للسلعة على المحور الأفقي للرسم - ويشار إلياه إلهها هنا بالرمز (P=n:1) بمعنى أن سعر الوحدة للصنف الجيد في السوق يعادل

$$
\text { سعر (n)وحدات من الصنف الأقل جودة. }
$$

(2)معدل ربا الفضل المحظور على المحور الراسي

ويشار إليه بالرمز (F=m:1) بمعنى أن صاحب الصنف المعال

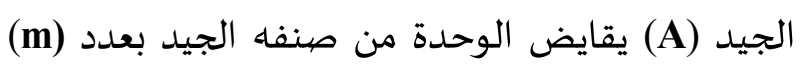
وحدات رديئة من صاحب الصنف الرديء (B). ينطلق هذا النموذج من $(1,1)$ باعتبارها نقطة الأصل التي ينتفي عندها فضل الجودة عن معدل تبادل السوق كما ينتفي ربا الفضل (P=1:1) يكون صفرًا في نقطة الأصل. وسوف يتم توظيف هذا يلتها

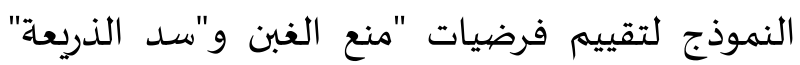
وإسقاط التنعم" كما سبق توضيحهها أعلاه.
ثالثًا: فرضية إسقاط غرض التنعم: وهي رأي أبي حامد الغزالي بقوله: (وإما جيد برديئين فقد يقصد، ولكن لما لماني كانت الأطعمة من الضروريات والجيد يساوي الرديء في أصل الفائدة ويخالفه في وجوه التنعم، أسقط الشرع غرض التنعم فيما هو القوام، فهذه حكمة الشرع في

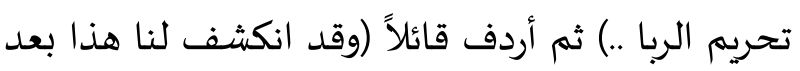
الإعراض عن فن الفقهيات، فلنلحقه بفن الفقهيات)

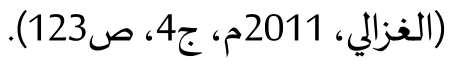

$$
\text { 4. تقييم الفرضيات البديلة }
$$

عليه، يبدو أن هناك حاجة إلى تطوير إطار تحليلي يساعد على تقويم كل من الفرضيات الثلاث أعلاه ومقابلتها بفرضية درء الاحتكار حسبما تم استنباطها في الجزء الثاني

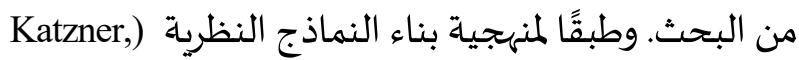
2016)، فسوف يتم إجراء المقارنة المطلوبة من خلال مجتمع نموذجي يستهلك سلة من السلع المطعومة والمقتاتة

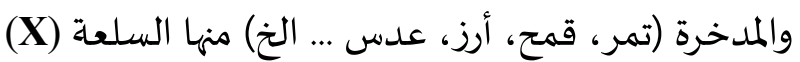
مدار البحث، بافتراض أن لها صنفان فقط: صنف عالي

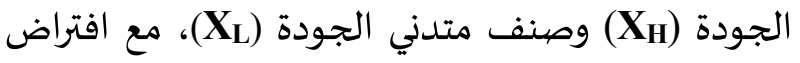

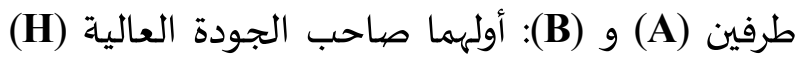
وثانيهما صاحب الجودة المتدنية L وأن كل منهما يهدف لتكبير منفعتاه من عملية المقايضية السلعية. لكن مطلب الواقعية في عملية التبادل السلعي يقتضي تبني افتراضين (assumptions) أساسيين في هذا الاطار التحليلي: a ت تفاوت السعرمع الجودة: بمعنى أن الجودة ظاهرة

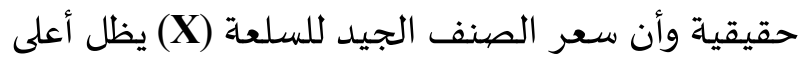
من سعر الصنف الرديء علمًا أن الشارع لا ينهى عن حصول الصنف الجيد على سعر أعلى من البديل الأقل جودة ولا يتدخل في عملية التسعير إلا لظروف استثنائية، 
1/4 تقييم فرضية منع الغبن

القطر: (P< خارج القطر (P=F) حيث ينتفي افتراض كفاية المعلومات. أما إذا تبين أن تحقق شرط الكفاءة المعلوماتية لا يمنع وقوع ربا الفضل، فهذا كاف للقول أن فرضية الغرر المفضيي

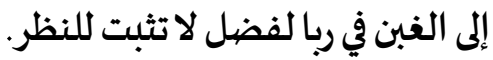
والأمر الغالب واقعيًا أن تسود كفاية المعلومات في سوق السلعة كما هي متضمنة في الافتراضين (a) و (b) أعلاه ومن ثم تحقق الشرط (m=n) تلقائيًا بين الطرفين (A) و(B). وهذا الافتراض تعززه قصة صاحب النخلة في الحديث الذي رواه مسلم عن أبي نضرة عن أبي سعيد الخدري رضي الله

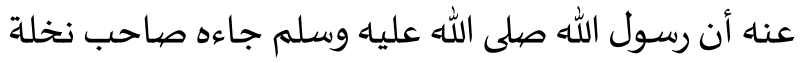
بصاع من تمر طيب [ أي عالي الجودة] وكان تمر النبي صلى جالى الله عليه وسلم هذا اللون [ أي الأقل جودة] فقال له النبي صلى الله عليه وسلم: (أنى لك هذا ؟) قال: (انطلقت بصاعين فاشتريت به هذا الصاع، فإن سعر هذا في السوق كذا وسعر هذا كذا)، فقال له النبي صلى الله عليه وسلم: (ويلك أربيت، إذا أردت ذلك فبع تمرك بسلعة ثم اشتر بسلعتك أي تمر شئت). فلم يشفح لصاحب النخلة أنها يعرف سعر السوق لكلا الصنفين وأنه أجرى ربا الفضل بناءً على هذا العلم، فهذا الدليل الشرعي يعضد النتيجة التي توصلنا إليها أعلاه بأن عدم كفاية المعلومات وقابلية وقوع الغبن على الطرف (B) بسبها ليس هو المفسدة

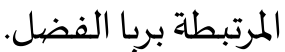

من أهم دلالات " نموذج إمكانات الغبن" أن الغبن في ربا الفضل ليس ملازمًا للطرف (B) بل يمكن وقوعاه على أي من الطرفين (A) أو B اعتمادًا على المقارنة بين معدل تبادل السوق (P=n:1) ومعدل تبادل ربا الفضل (F=m:1). فالنقاط الواقعة على المحور الراسي تمثل أقصى الغبن الواقع على الطرف B لأن فضل الجودة ينتفي عن معدل تبادل السوق (P=1:1) بينما يتزايد معدل ربا الفضل بلا حدود على طول المحور الرأسي (F=m:1). وفي

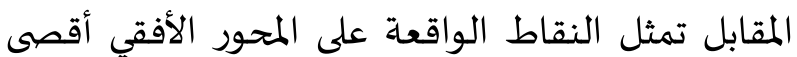
الغبن الواقع على الطرف (A) لأن ربا الفضل منعدم عند

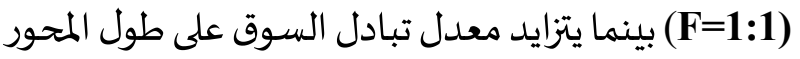
الأفقي P=n:1 بلا حدود. وفي كلا الحالتين لا يقع الغبن في تبادل ربا الفضل إلا بانتفاء افتراض الكفاءة المعلوماتية

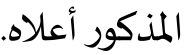

لكن من أهم دلات هذا النموذج أن الغبن ليس ملازمًا لربا الفضل، فهو ينتفي تمامًا على طول القطر الممتد

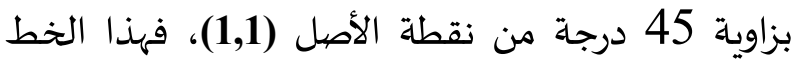
يتحقق فيه افتراض الكفاءة المعلوماتية حيث يتساوى

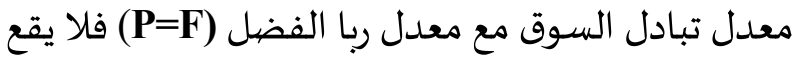
الغبن على أي من الطرفين. (A) و (B) رغم تعاملهما بمعدلات ربا الفضل . عدا ذلك، فإن الغبن في ربا الفضل الفيل قد يقع على الطرف (A) في المنطقة الواقعة أسفل القطر: (P>F) 
شكل (2): إمكانيات الغبن في مقايضية أصناف ربا الفضل بين الطرفين A و B

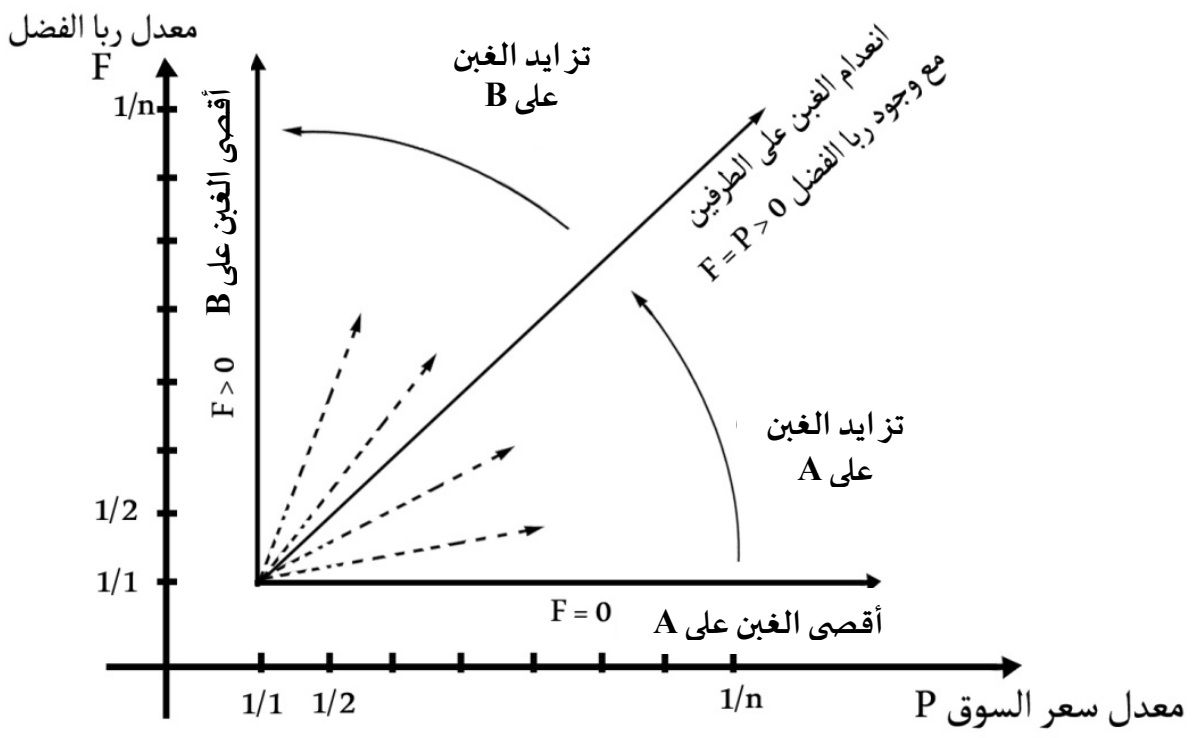

المصدر: من إعداد الباحث.

2/4 تقييم فرضية سد الذربعة

عندما تقل نسبة فضل الجودة عن نسبة ربا الفضل (P>F) بينما تغيب هذه المعلومة تمامًا عن الطرف (B) فيتزايد عليه الغبن مع تزايد زاوية الانحراف عن نقطة الأصل (F=1:1, P=(1.1) حتى يبلغ

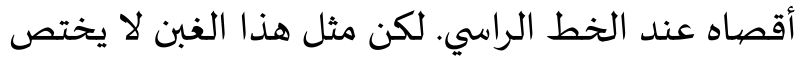
بربا الفضل فقط بل يمكن حدوثه في كل صور البيع

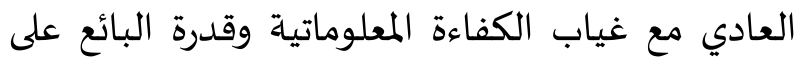
فرض سعر أعلى من سعر السوق وتحقيق ريح فاحش. وعليه، يمكن إبراز الملاحظات التالية عن طبيعة الريح

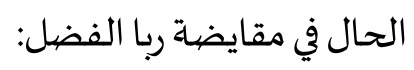

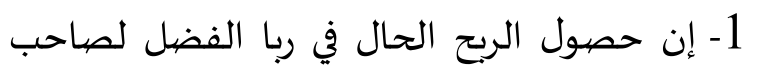

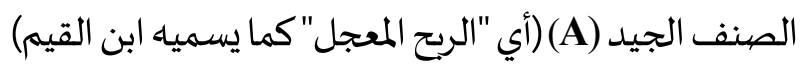

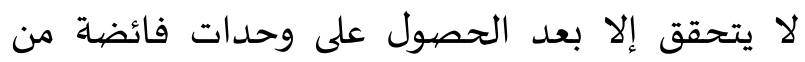
الصنف الأقل جودة (m-n) فوق ما يستحقه فضل إلإل
سبقت الإشارة أعلاه إلى رأي الإمام ابن القيم رحماه الله بأن ربا الفضل لا ينطوي على مفسدة سوى أنه ذريعة قريبة جدًا للوقوع في ربا النساء، والحجة في ذلك أن حلاوة "الريح المعجل" في ربا الفضل تغري الطرف (A) صاحب لياء الصنف الجيد إلى التطلع نحو "الريح المؤخر" في ربا النساء باعتباره المفسدة المقصودة بالدرء. لكن نموذج "إمكانات

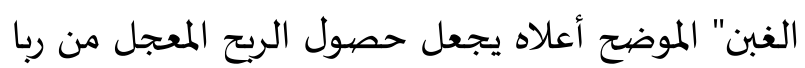
الفضل رهين بوقوع الغبن على الطرف (B) في ظل غياب الفيات الكفاءة المعلوماتية، أي المنطقة (P>F) الواقعة أعلى الى

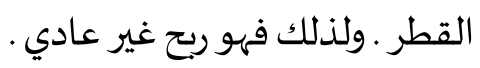

ولتوضيح هذه النقطة يمكن الرجوع مرة أخرى إلى إلى

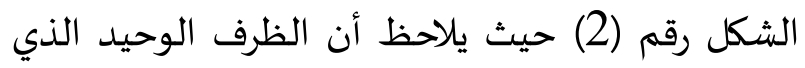
يتمكن فيه الطرف (A) من إيقاع الغبن على الطرف (B) وأكل ربا الفضل يكون في ظل غياب الكفاءة المعلوماتية 
2) أو أن يكون متمتعًا بسلطة احتكارية في سوق السلعة بمعنى القدرة على التأثير في السعر، فيصبح طامعًا في الرتح غير العادي في سوق السلعة بمختلف الوسائل الممكنة، بما في ذلك ربا الفضل والنساء.

والشاهد أن قوة الطلب الاستهلاكي على السلعة وتدني مرونتاه هما من أهم محفزات الربحية، وينطبقان خصوصيًا على السلع المدخرة والمقتاتة الأقل جودة. واذا اجتمعت مرتح معهما القدرة الاحتكارية للطرف (A) في تكوين رصيد كاف من المخزون السلعي للحد من العرض ورفح السعر، فإن إن اله مقايضات ربا الفضل - أي أخذ الكثير الأدنى جودة بالقليل الأعلى جودة - تسهه بطريقة مباشرة في بناء المخزون السلعي المؤثر على السعر حتى وان كان في ظل الكفاءة المعلوماتية. وهذا ينطبق كذلك على مقايضات ربا النساء حيث نبه إلهها الإمام ابن القيم بقوله: ( ... لو جاز بيع بعضها بعضيًا نساءً لم يفعل ذلك أحد إلا إذا ربح، وحينئنٍ تسمح نفسـاء ببيعها حالة لطمعاه في الربح فيعز الطعام على المحتاج ويشتد ضرره)، حيث تشير كلمة "حينئذ" إلى حصول الريح في المستقبل من

$$
\text { البيع الحال بسعر مجحف. }
$$

وعلى ذلك، فإن الربح الناتج عن ربا الفضل في ظل الكفاءة المعلوماتية لا يكون إلا "مؤخرًا"، تمامًا مثل الربح

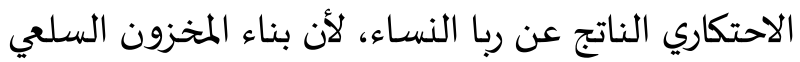
مع ترقب حركة الأسعار وخلق الشح في العرض يحدث بالتدريج ويحتاج إلى وقت كاف قبل أن ينعكس في رفح

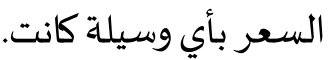

\section{3/4 تقييم فرضية إسقاط غرض التنعم} من الواضح أن الإمام أبا حامد الغزالي رحماه الله كان

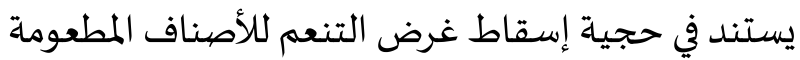
على الصورة الظاهرة للتبادل المشروع (مثلاً بمثل، يدًا
الجودة في سوق السلعة الحال، فيتحقق الربح تلقائيا من خلال بيعها بسعر السوق الجاري. لكن الحصول على هذا الربح رهين بإمكانية وقوع الغبن على صاحب الصنف الأقل جودة (B) وهذا لا سبيل إليه في ظل الكفاءة المعلوماتية لسوق السلعة، وقد أوردنا حيث صاحب النخلة كمثال واقعي تتحقق فياه الكفاءة المعلوماتية .

2- إن الربح الحال ربح غير عادي (abnormal Profit) يرتبط باختلال السوق عن الشروط التنافسية التي تقضي توفر الكفاءة المعلوماتية، علمًا أن صاحب الصنف الجيد يمكناه أن يحقق ربحًا عاديًا (normal profit) في ظل توفر الشروط التنافسية في سوق السلعة، ودون الحاجة إلى

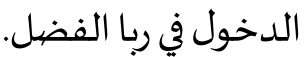
نخلص من ذلك إلى أن "الربح المعجل" من ربا الفضل حسب تعريف أعلاه مفسدة في ذاته وليس مجرد ذربعة لربا النساء لأنها ربح غير عادي في ظل عدم كفاءة المعلومات وناتج عن مجن قدرة الطرف (A) على إيقاع الغبن على الطرف (B). أما وقد سبق التخلي عن فرضية الغبن في المبحث أعلاه

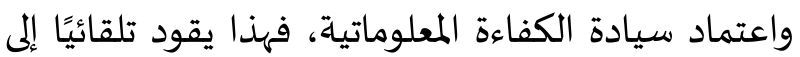
طرح السؤال البديل وهو: كيف يحقق صاحب الصنف الجيد ربحًا من ربا الفضل في ظل الكفاءة المعلوماتية واستبعاد الغبن، وهل ثمة اختلاف عن طريقة الاسترباح من ربا اللسـاء؟ والإجابة بطبيعة الحال تعتمد على المركز التنافسي للطرف (A)، الذي يتراوح بين أمرين: 1) أن يكون متلقيًا للسعر (Price Taker) في ظل توفر شروط المنافسة الكاملة، وحينئذ يصبح عاجزًا عن التأثير على السعر لتحقيق ربح غير عادي في سوق السلعة، لا من ربا الفضل ولا من ربا النساء، ويظل قانعًا بالربح العادي في السوق التنافسي. 
2) أن المصلحة المعتبرة في المتاجرة في الطعام هي ضرورة انتقاله مباشرة من البائع باعتباره الطرف المستغني عن منفعته إلى المستهلك النهائي الراغب في منفعته

3) أن أقرب دليل للحاجة الاستهلاكية للطعام في سوقه هي شراؤه بثمن من غير جنسه فيكون احتكار الطعام بغرض التجارة بين المتعاملين هو المفسدة المحظورة في التعامل بربا البيوع (الفضل والنساء)

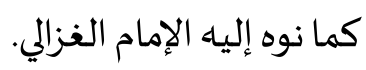
5 - تقييم فرضية درء الاحتكار يبدو من المبحث السابق أن فرضية درء الطمع الاحتكاري في الأقوات هي التي المقصد الشرعي من حظر ربا

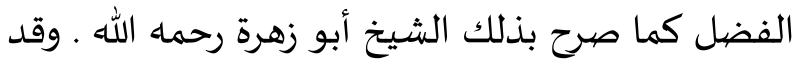
أصاب الإمام الغزالي باعتبار دليل الحاجة إلى الطعام

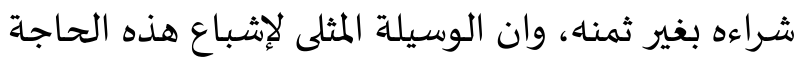

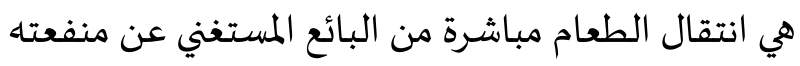
الغذائية إلى المستهلك النهائي الراغب في تلك المنفعة.

وعلى ذلك، يكون قول النبي صلى الله عليه وسلم: (بع الجمع واشتر بثمنه الجنيب) توجيها لصاحب الصنف الأقل جودة (الطرف B) لعرض سلعته على طرف يحتاج إلهيا طعامًا (الطرف C في الرسم التوضيحي) بدلاً من عرضها على صاحب الصنف الجديد ذي الطمع الاحتكاري في السوق (الطرف A)، فالأول أمر بالمعروف والثاني نهي عن المنكر؛ أنظر الرسم التوضيحي أدناه.
بيد)، لكن لا يصح القول أن إسقاط غرض التنعم هو هي الحكمة من تحريم ربا الفضل لأن النبي صلى الله عليه

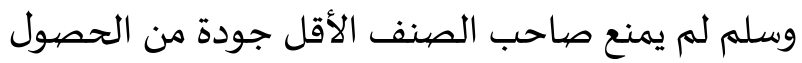
على الصنف الأعلى جودة بقوله "بع الجمع واشتر بثمنه

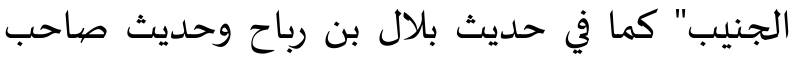
النخلة سابق الذكر، كما أن التسليم بوجود فضل الجيل الجودة (P=n:1) وعدم معارضته لأي أصل شرعي دليل كاف على عدام إسقاط غرض التنعم بالمعنى الذي بشير إليه الإمام الغزالي. ومع ذلك، فإن الإمام الغزالي رحمه الله قد أشار إلى علاقة ربا الفضل بالنزعة الاحتكارية في حق الذين يتجارون

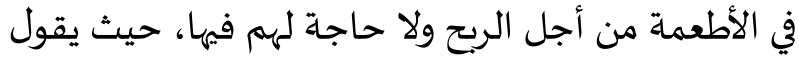

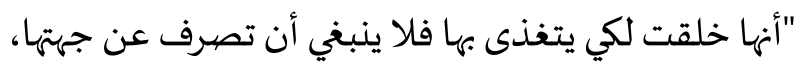

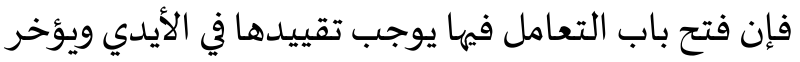
عنها الأكل الذي أربدت له، فما خلق الله الطعام إلا ليؤكل.

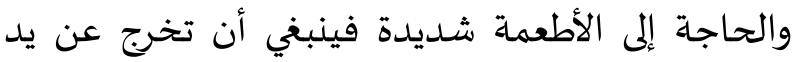

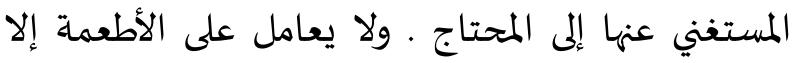

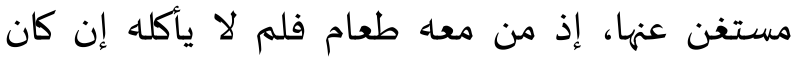

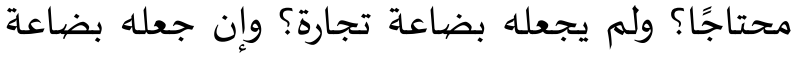
تجارة فليبعاه ممن يطلبه بعوض غير الطعام يكون محتاجًا إليه. فأما من يطلبه بعين ذلك الطعام فهو أيضًا مستغن

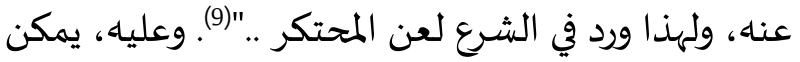
الخلوص من مقالة الإمام الغزالي إلى العبر الثلاث التالية: 1) أن عبارة "تأخير الأكل" تعنى بالمصطلح الحديث تأخير وصهول السلعة إلى المستهلك النهائي. 


\section{شكل (3): تبادل الجمع/الجنيب بحسب التوجيه النبوي}

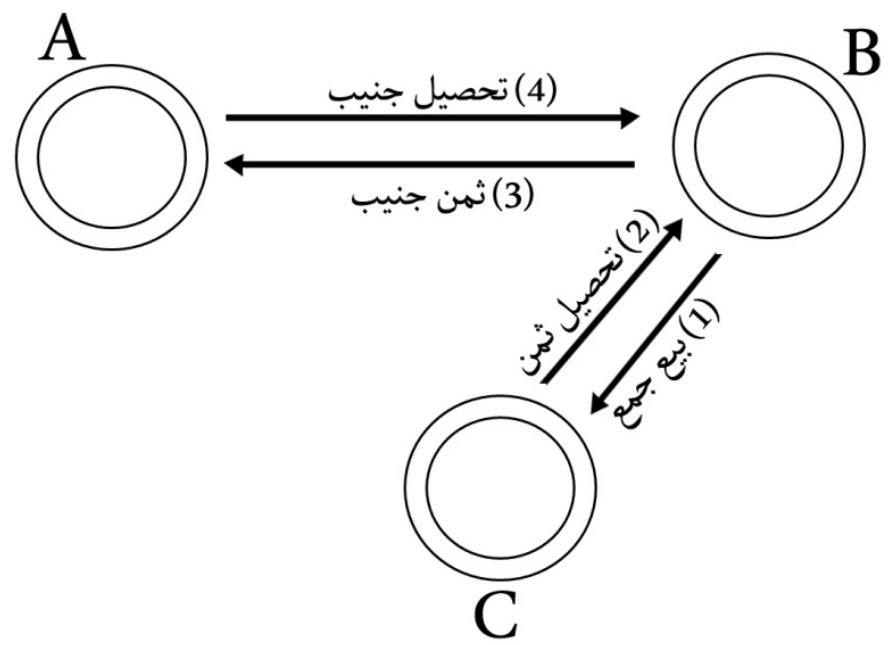

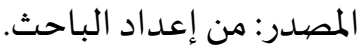

السوق عامة، أو حيث يقصيد، أو ينادي عليه ...) (ابن القيم، (د.ت.)، ج2، ص102). ومع أنه ليس من المتيقن أن لن آن كل من يقايض صنفًا جيدًا مع الفضل بصنف أقل جودة

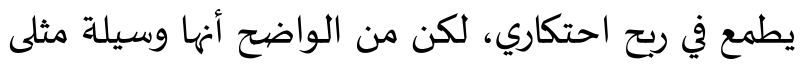

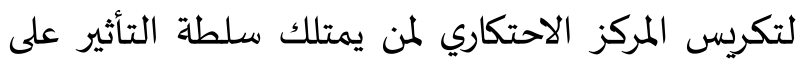

$$
\text { سعر السلعة في السوق. }
$$

لكن الإمام محمد أبو زهرة رحماه الله أضاف مقصدًا آخر إلى حكمة درء المفسدة الاحتكارية في الأقوات بقوله: (والفائدة الثانية أن قيمة الفرق تتعين يقينًا دقيقًا لا غبن فيا إذا دخلها المقياس النقدي الذي يقوَم الأشياء والمواد) (أبو زهرة، 1999م، ص57) أي أن حظر ربا الفضل

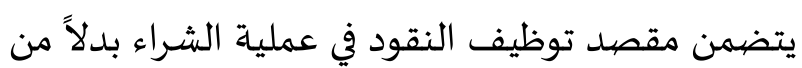
طريقة المقايضهة السلعية، استنادًا لقوله صلى الله عليه وسلم"... اشتر بالثمن الجنيب"، ومن الذي تابعوه في هذا
وعليه، يجب التأكيد بأن هذا المقصيد ينبني على الظن

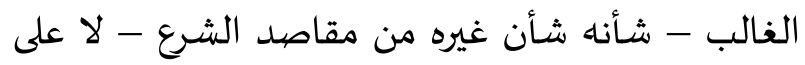

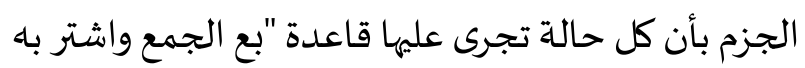

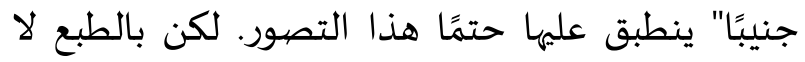

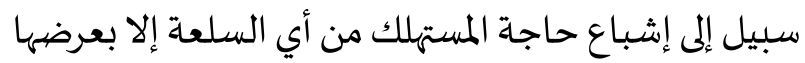
في سوقها بثمن. وهنا لا بد من استبعاد المعاملة الصورية المتمثلة في بيع السلعة للطرف (A) بثمن ثم عادة ذات الثمن إليه لشراء الصنف الأعلى جودة، فتلك هي عينة ربا الفضل التي استبعدها الإمام ابن القيم بقوله: ( ....

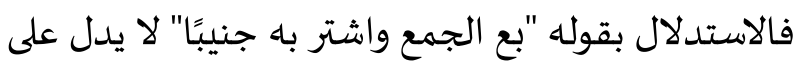
بيع العينة بوجه من الوجوه، فمن احتج باه على جوازه

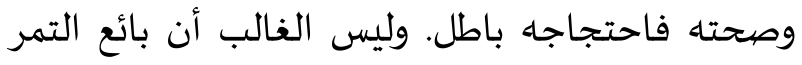
بدراهم يبتاع من المشتري حتى يقال هذه هي الصورة

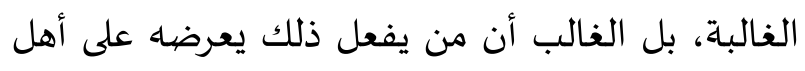


والمعيار المناسب لتقييم الفرضية يستند إلى النظر في

مدى إمكانية ظهور ربا الفضل - أي تبادل (X) و (X) مع الفضل - في ظل شروط الكفاءة المعلوماتية المفترضية وتوفر شروط المنافسة الكاملة، علمًا أن هذه الشروط كافية وضرورية لتبادل السلع العادية التي لا تخضع لحظر ربا الفضل، فإذا أمكن التعامل بربا الفضل جنبًا إلى جنب مع مبادلات السلع العادية ضمن هذه الشروط، كان هذا

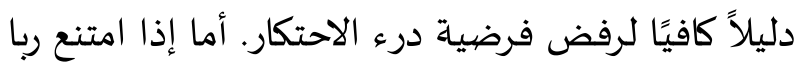
الفضل عن الظهور في ظل شروط الكفاءة المعلوماتية المفترضية وتوفر شروط المنافسة الكاملة، كان هذا دليلاً على صحة فرضية درء الاحتكار، وعندئذ يمكن تمثيل ربا الفضل بنموذج تبادلي يعكس نفس خصائص الفنية لتبادل السلع العادية ولكن في ظل دافعية الطمع الاحتكاري. لذا، سيتم التمثيل النموذجي لتوازن المستهلك على مرحلتين: (1) أولاً: في ظل توفر شروط المنافسة الكاملة في سوق السلعة (2) وثانيًا في ظل البيئة المواتية للطمع الاحتكاري. 2/5 المقايضية العادية في ظل المنافسة الكاملة: يحتاج تمثيل مجتمع المقايضية المفترض في ظل شروط سوق المنافسة الكاملة إلى إعادة صياغة نظرية توازن المستهلك وفقًا للخصيائص التالية:

(- استبدال أسعار السلع النقدية

(X, Y, Z, مجموعة مفترضة من السلع المتداولة:...etc.) $\left(P_{x / y}, P_{x / z}, P_{y / z}\right.$...etc.) بمعدلات المقايضة ....etc.) واعتبار معدلات المقايضة معطاة في نموذج افتراضي تتوفر فيه شروط سوق المنافسة الكاملة، باعتبار وجود عدد كبير من المنتجين والمستهلكين، متلقين لمعدلات المقايضية بلا سلطة لهم في التأثير عليها (Price Takers).
المقصد عبدالرحمن يسري(10). لكن من المعلوم أن "الثمن" ليس مقتصرًا على النقود بل يمكن أن يكون سلعة كما سبق ذكره أعلاه في حديث النبي صلى الله عليه وسلم لصاحب النخلة: (... إذا أردت ذلك فبع تمرك بسلعة ثم اشتر بسلعتك أي تمر شئت) ، وهذا كاف للقول بأن حكمة حظر ربا الفضل هي إشباع حاجة الطرف النموذجي (C) من الطعام (أي المستهلك النهائي للسلعةة) سواء كان الثمن نقودًا أو أية سلعة أخرى، وذلك من لطف الشريعة السمحاء إذ لا يكلف الله نفسًا إلا وسعها. ولو حُمل الثمن على النقود لشق ذلك على أكثر الناس وفقًا لحال المجتمع في العصور السالفة كما وصفه ابن القيم رحمه الله بقوله: (وعامة أهل الأرض ليس عندهم دراهم ولا دنانير، لا سيما

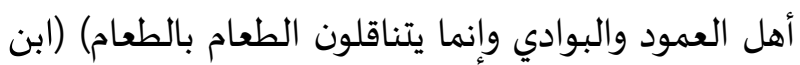
القيم، المرجع السابق، ج2، ص138). 1/5 معيار التقييم الآن يمكن إبراز المقصد تحليليًا ضمن الاطار التحليلي السابق وشروط الكفاءة المعلوماتية المعبر عنها بالافتراضين (a) و(b) أعلاه، وذلك من خلال "نموذج التوازن في ظل تفاوت الجودة" لتقييم فرضية درء الاحتكار، علمًا أن هذا النموذج لا يعدو عن كونه تطبيق مباشر لنظرية توازن المستهلك كما هي معهودة في مداخل الاقتصاد الجزئي، ولكن على أساس سلعتين مختلفتي الجودة - سلعة جيدة وأخرى رديئة (Paul \& Robin, 2018, pp. 310-311) وتوفر شروط المنافسة الكاملة في هذا السوق - مع افتراض مجتمع يتناقل فياه الناس الطعام بالطعام مقايضية، حيث يشار بالرمز (X) للسلعة الجيدة وبالرمز (X) للسلعة الرديئة.

(10) انظر تعليق الدكتور عبدالرحمن يسري، المنشور في الكتاب بعنوان: Sustainable Development: an Evaluation of Conventional \& Islamic Perspectives in 'Islamic Perspectives on Sustainable Development' edited by M. Iqbal, Palgrave, pp.51 - 55, 2005 
التبادل من خلال خط المقايضة السلعياة. وعلى ذلك، يكون شرط الدخول في عملية المقايضية بالنسبة للمستهلك النموذجي المنتج للسلعة (X) والراغب في الحصول على السلعة (Y) - (Y) هو:

$$
\operatorname{MRS}_{\mathbf{x} / \mathbf{y}}>\mathbf{P}_{\mathbf{x} / \mathbf{y}}
$$

بمعنى أن المستهلك يمتلك فائضيًا إنتاجيًا من السلعة التي ينتجها مقابل عجز استهلاكي في السلعة الأخرى (X) التي يود الحصول عليها، ولاستعادة التوازن يدخل (Y) المستهلك في عمليات مقايضة مع بعض أطراف السوق ئون ههدف تكبير المنفعة من خلال مقايضية (X) بـ(Y). والاستمرار في هذه العمليات حتى يتحقق الشرط التوازن:

$$
\operatorname{MRS}_{\mathbf{x} / \mathbf{y}}=\mathbf{P}_{\mathbf{x} / \mathbf{y}}
$$

فذلك هو نموذج المقايضة السلعياة العادية وفقًا لنظرية سلوك المستهلك المتعارف عليها، حيث ينتقل المستهلك من منحنى سواء إلى منحنى أعلى منه حتى يتوقف

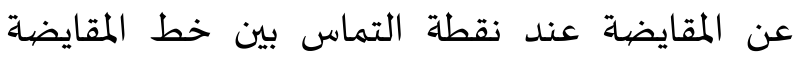
السلعية وأعلى منحنى السواء يمكن الوصول إليا (طبعًا مع استبعاد السلع المحرمة عن مجموعة السلع المتداولة،

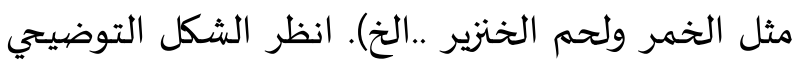
رقم (4):
2- تعريف دخل المستهلك (Consumer's Income) بالرصيد السلعي المتوفر لديه بدلاً من الرصيد النقدي المتعارف عليه في مداخل علم الاقتصياد، ومن ثم استبدال خط الميزانية النقدي (Budget Line) بخط المقايضية السلعية (Commodity Barter Line) .

3- في غياب النقد كوسيط للتبادل يكون الفرد منتجًا ومستهلكًا في آن واحد من خلاب النعل خوسيطل مقايضية سلعتا بسلع الآخرين، ولأجل تبسيط التحليل والتركيز على الأسئلة المحورية، يفترض أن المواءمة بين الأطراف في سوق

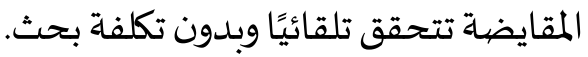
4- أن هدف المستهلك النموذجي من الدخول في

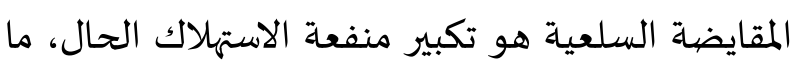
يعني أن عملية المفاضلة بين السلع رهينة بمقارنة منافعها الاستهلاكية الحالة. وبما أن مدار التركيز في هذا المبحث يقتصر على ظاهرة تداول السلع في السوق فيمكن افتراض أن كلا الطرفين لدياء نفس منحنى الإمكانات الإنتاجية (PPC) كما هو موضح في الرسم وإنما يختلفان فقط في منحنيات السواء التي تعكس اختلاف تفضيلاتهما للسلعتين وحاجتهما إلى 


\section{شكل (4): تحسن المنافع بسبب التبادل}

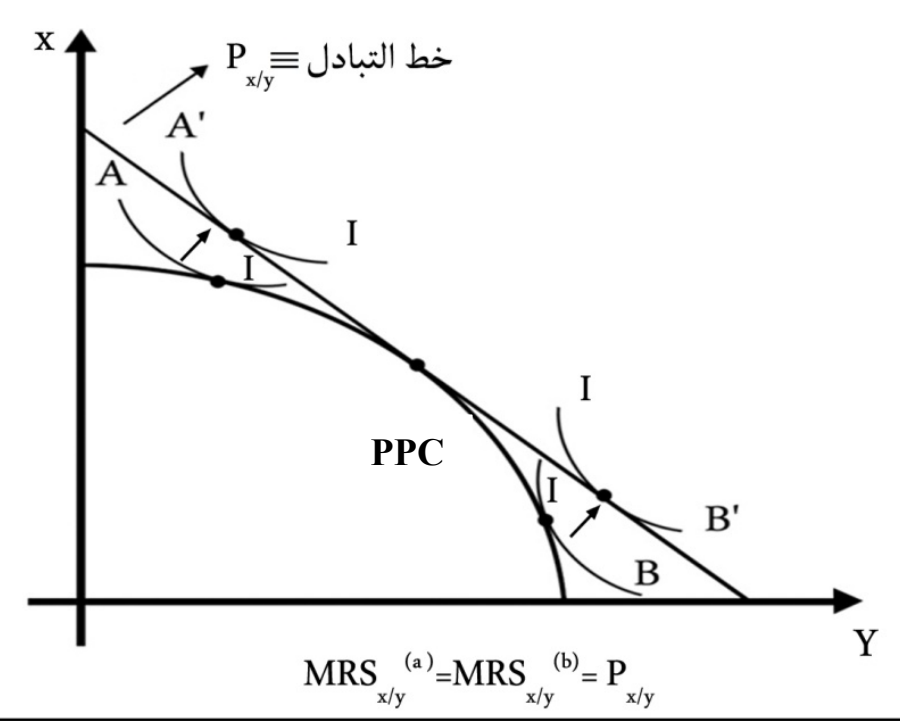

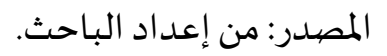

(2) وهل تنطبق نفس شروط مقايضية السلع العادية - شرطا الدخول في المقايضية وتحقيق التوازن - على المقايضية المحظورة ؟ لمادئ

فإذا تبين لاحقًا أن المقايضية المحظورة تختلف تحليليًا عن المقايضة العادية كما هي موضحة أعلاه وأنها ترتبط سلوكيًا بمشكلة الانحراف عن نموذج المنافسـة الكاملة دل ذلك على إمكانية ارتباطها بالطمع الاحتكاري

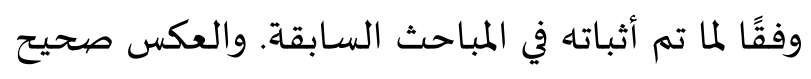

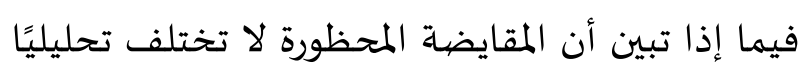
عن المقايضة العادية في ظل المنافسـة الكاملة.
ويترتب على هذه التحليل النموذجي تحقيق المصلحة المعتبرة في تداول السلع الاستهلاكية كما أشار إليها الإمام

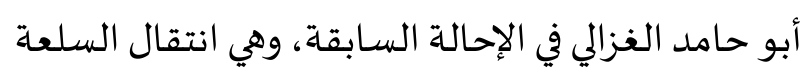

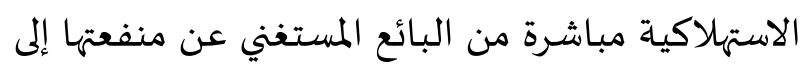

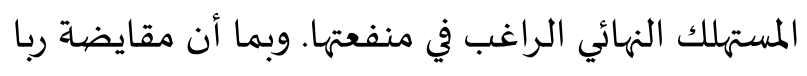
الفضل المحظورة لا تختلف شكليًا عن مقايضية السلع العادية سوى كونها بين صنفين جيد وردئ لنفس السلعة مع فضل الجودة، فالتساؤل المحوري هو: هل هلئ

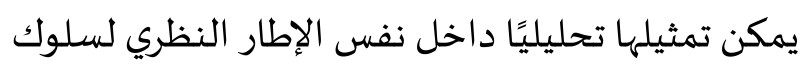
المستهلك في ظل شروط المنافسة الكاملة؟ وهذا بدوره يتفرع إلى سؤالين أساسيين:

(1) ما هي نقطة الافتراق بين مقايضية السلع العادية والمقايضة المحظورة لصنفين جيد وردئ في

ظل المنافسة الكاملة؟ 
3/5 الافتراق عن المقايضية العادية

مع كون (C>1) تأكيدًا لأفضلية الجيد على الرديء عند كل مستويات الاستهلاك. وبناءً على ذلك، سوف تكون أسرة منحنيات سواء المنفعة خطوطًا مستقيمة منحدرة إلى أسفل وميلها المطلق أكبر من الواحد الصحيح بالنسبة للمستهلك النموذجي كما يمثله

$$
\text { الشكل التوضيحي رقم(5). }
$$

2) غلاء الجيد ورخص الرديء بحيث يكون معدل مقايضة الرديء بالجيد في السوق أكبر من الواحد الصحيح لهيح ( ، وسوف يشار إليه هنا بمعدل تفضيل السوق. مثلاً (P/L/L) تعني جيدًا برديئين كما هو دارج في التمثيل الفقهي الموروث. وبناءً على ذلك، يكون الميل المطلق لخط المقايضة السلعية اكبر من الواحد الصحيح كما يمثله الخط المتصل في الشكل التوضيتي رقم (7).
تفترق المقايضة المحظورة عن المقايضة المشروعة في النقطة الجوهرية التي أشار إليها الإمام أبو حامد الغزالي

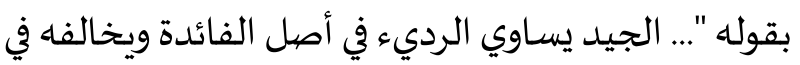
وجوه التنعم ..." وباستخدام منحنيات السواء، نجد أن لن ذلك يعني تطابق فائدتهما الاستهلاكية مع تفاضل جودتهما النوعية، أي أن الصنف الجيد (X) يظل دائمًا مفضلاً بين أفراد المجتمع على الصنف الرديء (XLL) من الوجهة الاستهلاكية، وأن الرديء لا ينطوي على أي ميزة على الجيد سوى رخص الثمن. وهذا ينعكس على منحنيات سواء المنفعة وخط المقايضة السلعياة في وصفين أساسيين: 1) - (ببات معدل الإحلال الحدي بين الصنفين:

$$
\mathrm{MRS}_{\mathrm{H} / \mathrm{L}}=\mathrm{C}
$$

\section{شكل (5): منحنيات السـواء الخطية بين الجودة الأعلى XL والجودة الأقل X}

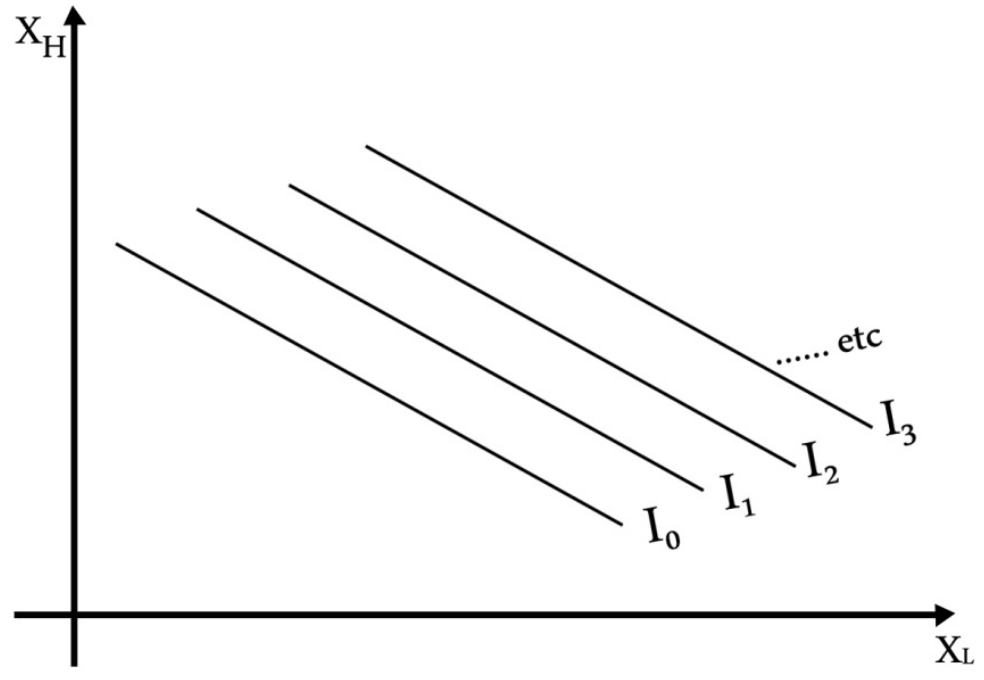

المصدر: من إعداد الباحث. 
وحينئذ تنطبق منحنيات السواء مع خط المقايضة السلعية

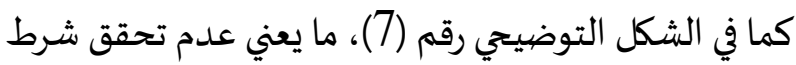

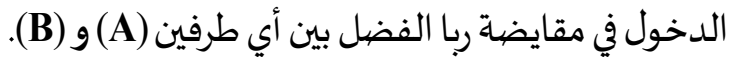
ثالثًا: يمكن أن يحقق بعض الأطراف منفعة استهلاكية

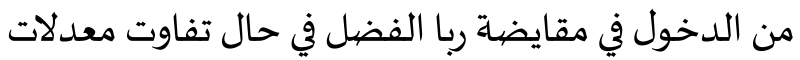
الإحلال الحدي بين الأفراد لكنها تتم بحلولِ ركنية خلافًا

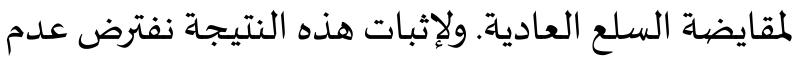
تساوي معدلات الإحلال الحدي الفردية

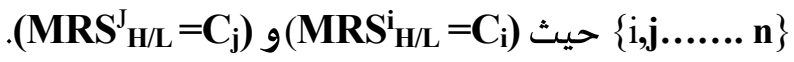
وحينئذ يمكن أن يتحقق الشرط $\left(\mathbf{C}_{\mathrm{A}}>\mathbf{P}_{\mathrm{H} / \mathrm{L}}>\mathbf{C}_{\mathrm{B}}>1\right)$ للدخول في مقايضة ربا الفضل بين الطرفين (A) و(B)، فينتقل كل منهما إلى منحنى سواء أعلى فأعلى حتى يتوقفا عند نقطة توازهما ولكنهما حلين ركنيين (corner solutions) كما يوضحه الشكل التوضيحي رقم (8)، وهو بالطبع ينافي

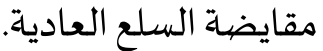

وبناءً على الوصفين أعلاه يمكن استنباط النتائج التالية: أولاً: إن الميزة الوحيدة للرديء على الجيَّد هي رخص السعر. ولإثبات هذه النتيجة نفترض أن الصنفين لهما

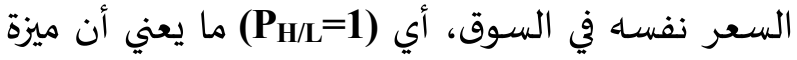

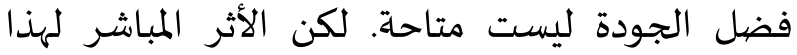

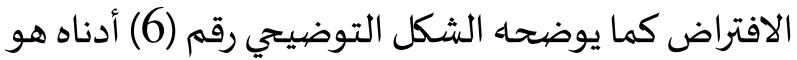

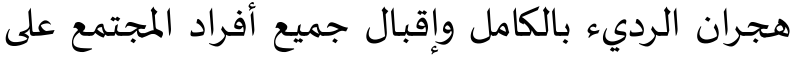

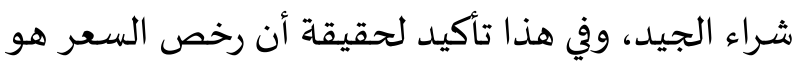
المبرر الوحيد لوجود السلعة الرديئة.

ثانيًا: لن يحقق أي من الطرفين (A) و (B) أي منفعة

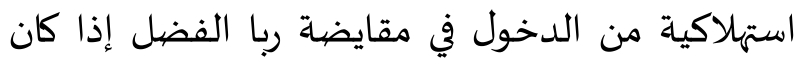
معدلات الإحلال الحدي لأفراد المجتمع مساوية لمعدل

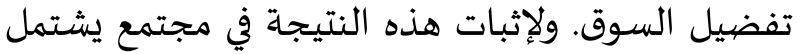

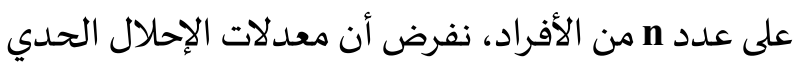

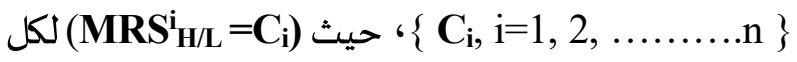
فرد (i) تتطابق مع معدل تفضيل السوق (C)

شكل (6): الإجماع الكلي للمستهلكين على تفضيل الصنف الأعلى جودة

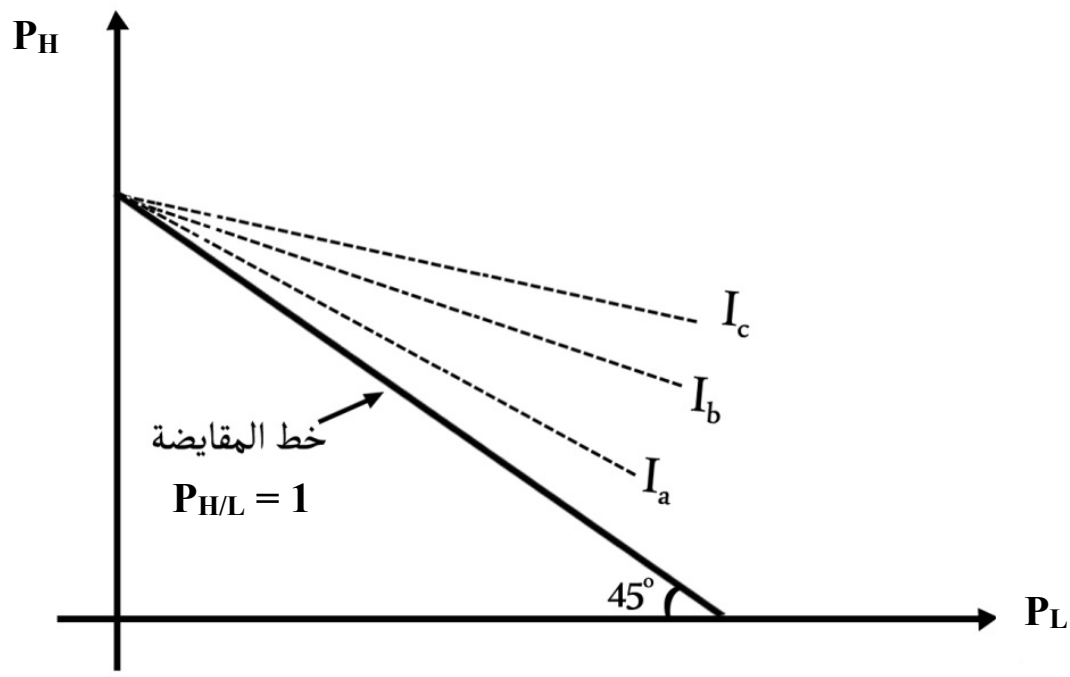

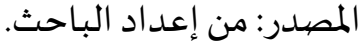




$$
\text { شكل (7): حالة خاصة لانعدام التبادل }
$$

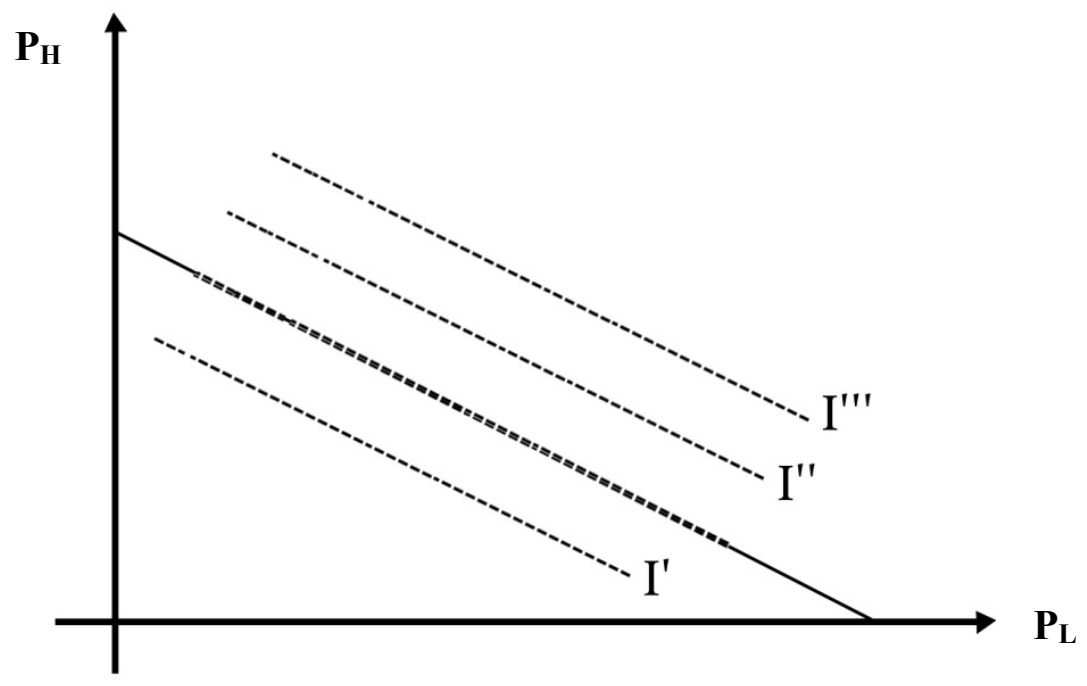

$$
\text { المصدر: من إعداد الباحث. }
$$

شكل (8): الحلول الركنية في حال اختلاف

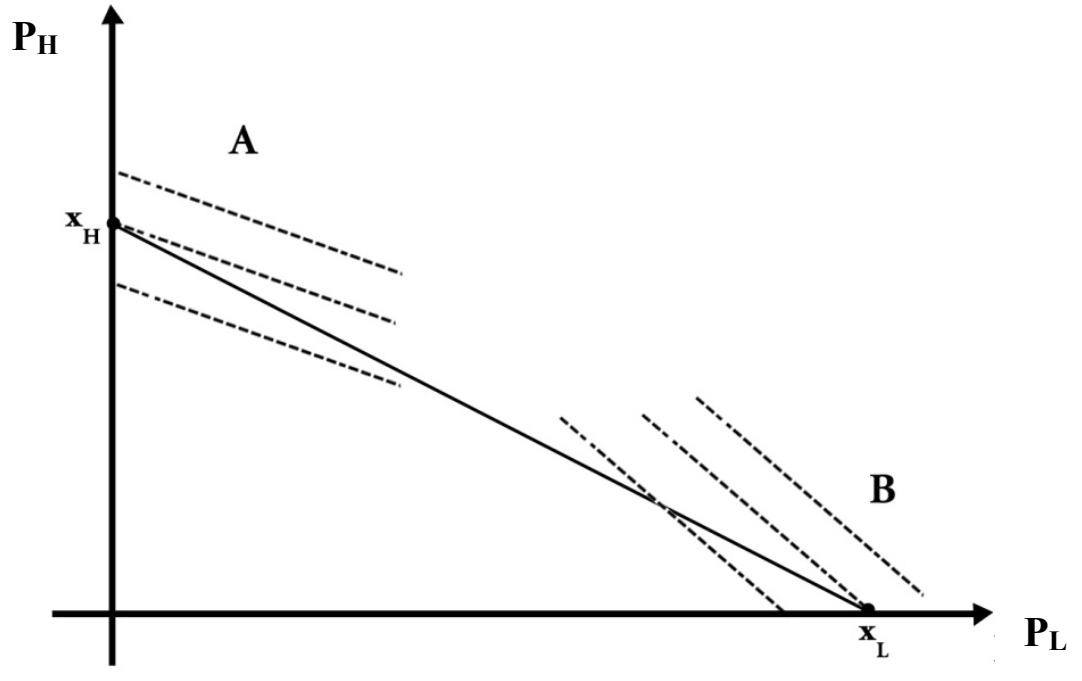

المصيدر: من إعداد الباحث. 
المستهلك النموذجي من الدخول في المقايضة السلعية هو تكبير منفعة الاستهالك الحال، ما يعني التخلي عنها واستبدالها بهدف آخر وهو الجمع بين منفعة الاستهلاك الحال والاستثمار الموجاه نحو زيادة الدخل المستقبلي. وبالطبع، لن تكون المفاضلة بين الجيد والرديء مقتصرة

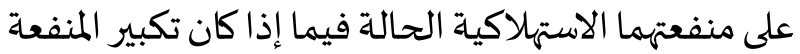
يجمع بين هدف الاستهلاك الحال وهدف الاستثمار. حينئذ لن يكون رخص السعر هو المزية الوحيدة للصنف الرديء كما في نموذج المنافسة الكاملة، بل سيكتسب هذا الصنف مزية استثمارية فريدة تتمثل في أسرة من فئ فئل منحنيات السواء المقعرة والتي تلائم مقايضية السلع العادية كما في الشكل رقم (1)، ما يعني التخلي عن ثبات

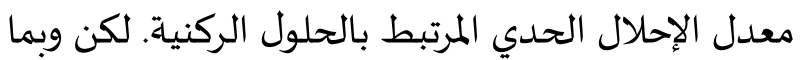
أن الطلب على الصنف الرديء قد أصبح طلبًا استثماريًا فذلك يقتضي لتخلي عن شرط تلقي الثمن في سوق

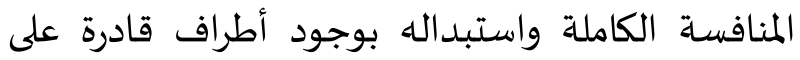
التأثير على السعر في مناخ احتكاري. وحينئذ تقع المفاضلة بين غرض الاستهلاك الحال الذي يمثله الصنف الجيد، وغرض الاستثمار المستقبلي

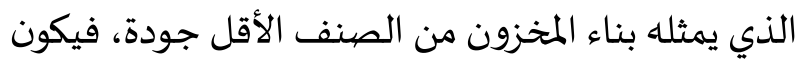
شرط الدخول في المقايضة المحظورة (MRSH/L مماثلاً لشرط الدخول في المقايضية العادية بين سلعتين مختلفتين، وكذلك الانتقال من منحنى سواء إلى آخر أعلى له

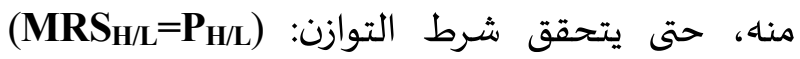
والتوقف عن المقايضية. وذلك هو السلوك النموذجي لصاحب الصنف اليد (A) كما تم تعريفه سابقًا؛ انظر الشكل التوضيتي رقم (9) أدناه .
وعليه، يتبين من النتائج الأخيرة أن مقايضية ربا الفضل تختلف تحليليًا عن مقايضة السلع العادية في ظل نموذج المنافسة الكاملة ، وذلك من ناحيتين: (1) عدم تحقق شرط الدخول في المقايضية المحظورة في حال تطابق معدلات الإحلال الحدي (2) الخلوص إلى حلول ركنية حال تفاوت معدلات الإحلال الحدي خلافًا للمألوف في مقايضات السلع

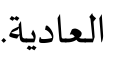

وبما أن مقايضية ربا الفضل لا تختلف شكليًا عن مقايضة السلع العادية في الواقع فذلك يعني عدم إمكانية

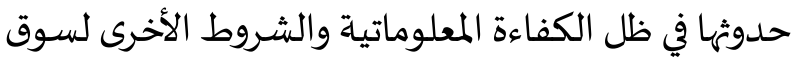
المنافسة الكاملة، وفي ذلك قبول لفرضية درء الاحتكار ومدعاة للنظر في إمكانية حدوث ربا الفضل في نموذج السوق البديل- أي سوق التحكم الاحتكاري في السعر.

4/5 المقايضية الربوية في ظل التحكم الاحتكاري إن تمثيل مقايضية ربا الفضل نموذجيًا يبدأ بمعالجة

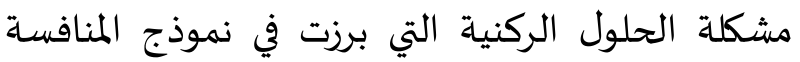

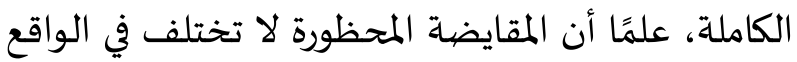
عن المقايضاة العادية للسلع من الناحية الشكلية، وان الحلول الركنية تعود في الأصل إلى ثبات معدلات الإحلال الحدي في اسر منحنيات السواء لأفراد المجتمع بين الصنفين الجيد والرديء من نفس السلعة كما سبق الصن توضيحها في الأشكال رقم (5، 6، 7 و 8) أعلاه. لذا، فإن لهن

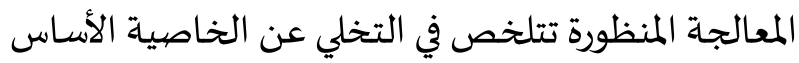
ضمن خصائص النموذج التنافسي لمقايضية السلع

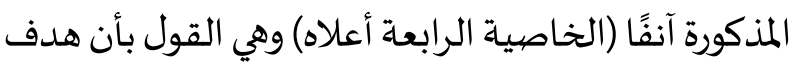


شكل (9): اختلاف الدو افع في الاحتفاظ بالصنفين X و X $X_{\text {I }}$ وظهور الاحتكار

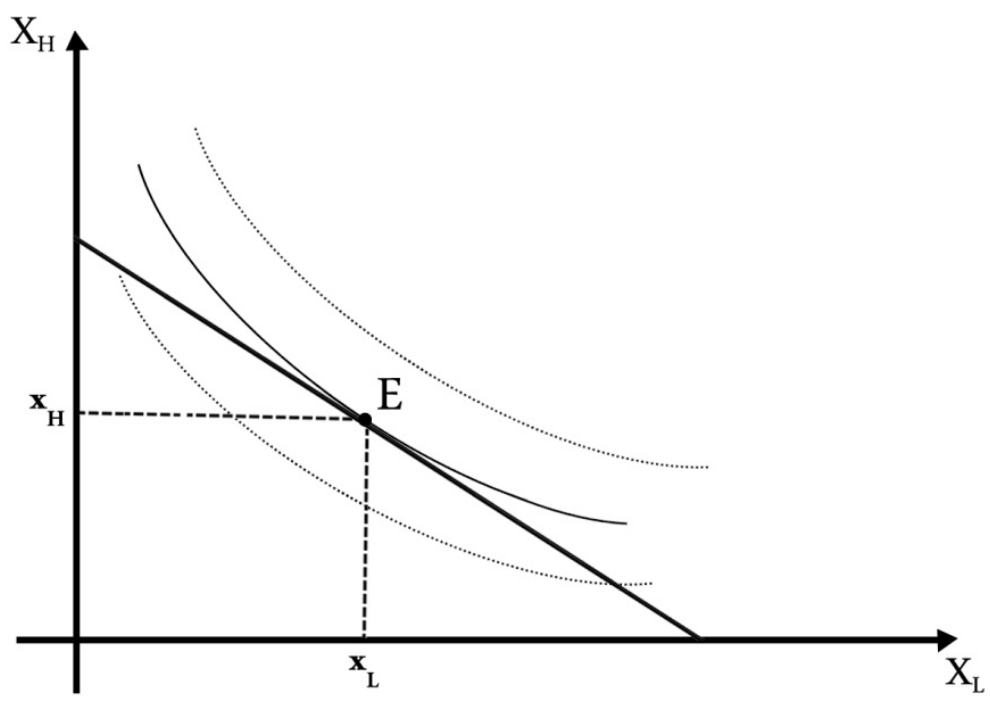

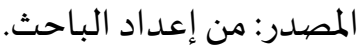

للسعر وتحوطًا ضد غلاء السعر المستقبلي. وعلى هذا النحو،

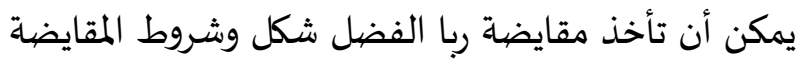
العادية ولكن في ظل الطمع الاحتكاري، وهكذا يتحقق التعزيز التحليلي المطلوب لفرضية درء الاحتكار.

المستهلك. ولكن نظرًا إلى شح الأبحاث التي تناولت ظاهرة الاحتكار في أدبيات الاقتصاد الإسلامي مع أنها من آفات إنات هذا العصر وأجدرها بالدراسـة، فهذا يدعو إلى بذل المزيد من الجهد التحليلي والفقهي لتأصيل هذا المقصيد الشرعي. وتبقي إلى جانب ذلك الحاجة إلى توسعة موضوع هذا البحث بالنظر في علة الثمنية في الذهب والفضية وكيفية تمثيل الظاهرة الاحتكارية من خلالها وهو من الموضوعات الجديرة بالبحث لتسليط الضوء على دلالاتها المقاصيدية.
وفي ظل هذا المناخ الاحتكاري يكتسب الصنف الأقل جودة ميزة استثمارية، ليس فقط من قِبَل الأطراف القادرة على التأثير في السعر المستقبلي (مثل الطرف A) من خلال بناء المخزون السلعي وإنما كذلك من قبل سائر أفراد المجتمع من مني بتكوين مدخرات محدودة من السلعة الأقل جودة ترقبًا

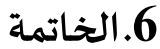

خلصت الورقة إلى تأكيد المقصد الشرعي من حماية شروط التنافس في الأسواق وكسر الأطماع الاحتكارية مهما خفيت حقائقها وتعددت صورها، وإلى ضرورة اعتبار هذا المقصد أساسًا استراتيجيًا للنظام الاقتصادي الإسلامي لكل زمان ومكان. وإذا صح هذا الاعتبار، فسيكون له أثر مباشر على معايير الإشراف الشرعي على معاملات المؤسسات المالية الإسلامية، والتي تركز غالبًا على ضمان التخلص من عنصريين فقط: الفائدة الربوية والغرر الفاحش، دون النظر إلى مراكزها الاحتكارية إن وجدت وضررها على 
الجزيري، عبدالرحمن بن محمد عوض. (2003م). الفقه على المذاهب الأربعة، الطبعة الثانية، بيروت: دار الكتب العلمية.

الزحيلي، وهبة (1989م) الفقه الإسلاهي وأدلته، دمشق: دار الفكر.

الشـاطبي، أبو اسحق (د.ت.) الموافقات في أصيول الشريعة، شرع عبدالله دراز، بيروت: دار الكتب العلمية.

عبد الكريم، بليل (2011م) أسلمة المعرفة: إعادة صياغة aluka.net/sharia/0/7/7442/ المصطلح،

عبيد، سعيد (2017م) أسلمة المعرفة: المفهوم والمشروع، msf-online.com موقع منتدى العلماء،

الغزالي، أبو حامد (2011م) إحياء علوم الدين، جدة: دار

$$
\text { المنهاج للنشر والتوزيع. }
$$

الفاروقي، راجي إسماعيل (1983م) أسلمة المعرفة: المبادئ العامة وخطة العمل، ترجمة الوارث سعيد، جامعة الكويت، الكويت: دار البحوث العلمية.

يسري، عبدالرحمن (1998م) تطور الفكر الاقتصادي الإسالامي، جامعة الإسكندرية، مصر.

Al-Faruqi, R. Ismail (1997) "Islamization of Knowledge", $3^{\text {rd }}$ edition, International Institute of Islamic Thought, Herndon, Virginia, USA

Al-Jaziri, Abd al-Rahman ibn Muhammad Awad. (2003). Al-Figh Alaa Al-Mzahib Al-Arbaah. 2 ${ }^{\text {nd }}$ Edition, Beirut: Dar al Kotob al-Alamiyya.

Katzner, Donald W. (2016) The Stages of Model Building in Economics, Studies in Microeconomics, SAGE Publications, India, Pvt. Ltd.

Paul Krugman \& Robin Wells (2018), 'Microeconomics' Macmillan Education.

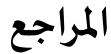

$$
\begin{aligned}
& \text { ابن العربي، أبوبكر (1992م) كتاب القبس في شرح موطأ } \\
& \text { مالك بن أنس، تحقيق د. محمد عبد الله ولد كريم، بيروت: }
\end{aligned}
$$

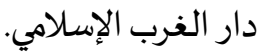

$$
\begin{aligned}
& \text { ابن القيم، شمس الدين محمد بن أبي بكر (1977م) إعلام } \\
& \text { الموقعين عن رب العالمين، بيروت: دار الكتب العلمية. } \\
& \text { ابن القيم، شمس الدين محمد بن أبي بكر (د.ت.) إغاثة } \\
& \text { اللهفان من مصايد الشيطان، تحقيق محمد حامد الفقي، }
\end{aligned}
$$

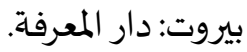

$$
\begin{aligned}
& \text { ابن رشد (الحفيد)، محممد بن أحمد (1995م)، بداية المجتهد } \\
& \text { ونهاية المقتصيد. بيروت، دار الفكر. } \\
& \text { ابن عبدالسلام، عزالدين (د.ت.) قواعد الأحكام في مصالح } \\
& \text { الأنام، بيروت: دار المعرفة. } \\
& \text { أبو زهرة، محمد (1999م) بحوث في الربا، القاهرة: دار }
\end{aligned}
$$

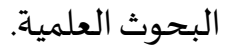

ثانيًا: المراجع الأجنبية

Pindyck \& Daniel L. Rubinfeld (3013), 'Microeconomics', Pearson

Tag el-Din (2013), 'Maqasid Foundations of Market Economics', EUP, UK

Tag el-Din (2017) Maqasid-Based Methodology of Islamic Economics, Proceedings of the $6^{\text {th }}$ Workshop on Islamic Economics, IKAM, Istanbul, Turkey.

Yusri, Abdelrahman (2005 ), Sustainable Development: an Evaluation of Conventional \& Islamic Perspectives published in 'Islamic Perspectives on Sustainable Development' edited by M. Iqbal, Palgrave. 


\section{Translation of Arabic References}

Abdelkarim, Belail. (2011). "Aslamat Al Ma'rifa: I'adat Siaghat Al Mustalah" "[Islamization of Knowledge" Re-formulating the Term], aluka.net/sharia/0/7/7442/

Abu Zahra, Muhammad. (1999). "Buhooth fi Al-Riba" [Researches in Riba]. Cairo: Dar Al-Bohooth AlIlmyya.

Al-Amidi, Ali Bin Muhammad. (n.d.). "Al-Ihkam Fi Usool Al-Ahkam" [Precision in the Origins of Rulings] . Beirut: Dar Al-Kitab al-Arabi.

Al-Gazali, Abu Hamid. (2011). "Ihiay Uloom Ad-Din" [Revival of Religion Sciences]. Dar Al-Minhaj Publishing \& Distribution - Jeddah - Saudi Arabia.

Al-Shatibi, Abu Ishaq. (n.d.). "Al-Muwafaqat fi Usool AlShari'ah" [Concordances in the Origins of Shariah]; Beirut: Dar Al-Qutub Al-Ilmyya.

Al-Zuhaili, Wahba. (1989). "Al-Fiqh Al-Islami wa Adillatuh" [Islamic jurisprudence and its Proofs]. Damascus: Dar Al-Fikr.

Ibn Abdussalam, Ezzeddine. (n.d.). “Qaw'id Al-Ahkam fi Masalih Al-Anam" [Norms of Ruling of People's Benefits]. Beirut: Dar Al-Marifaa.
Ibn Al-Arabi, Abu Baker. (1992). Kitab Al-Qabas Fi Sharh Muwatta Malik bin Anas. Inquest and Study of Mohamed Abdellah Ould Karim. Beirut: Dar AlGharb Al-Islami.

Ibn Al-Qayim, Shamsuddin Muhammad Bin Abi Baker. (1977). "Il'am Al-Muwaqyyin'An Rab Al-Alamin" [Informing the Signatories (the muftis) on Behalf of the Lord of the Words]. Beirut: Dar Al-Qutub Al-Ilmyya.

Ibn Al-Qayim, Shamsuddin Muhammad Bin Abi Baker. (undated) "Ighathat Al Lahfan min Masayid Al Shaytan" [Rescuing the Craver from the Traps of Satan], ed. Mohamed Hamid Al Fagi, Dar Al Ma'rifa, Beirut

Ibn Rushd, Muhammad bin Ahmad. (1995). Bidayat alMujtahid wa Nihayat al-Muqtasid [The Beginning for the Expert and the End for the Beginner]. Beirut, Lebanon: Dar al-Fikr.

Ubaid, Sa'id. (2017). “ Aslamat Al Ma'rifa:Al Mafhoom wa Al Mashru" [Islamization of Knowledge: The Concept and the Project], msf-online.com

Yusri, Abdelrahman. (1998). "Tatawor Al-Fikr AlIqtisadi al-Islami" [The Evolution of Islamic Economic Thought]. Alexandria: University of Alexandria. 
سيف الدين إبراهيم تاج الدين أستاذ الاقتصاد بكلية الاقتصاد والعلوم الاجتماعية، جامعة الإمام محمد بن سعود الإسلامية بالرياض. عضو مشارك في ملتقيات الدائرة المستديرة السنوية التي ينظمها برنامج جامعة هارفارد عن التمويل الإسلامي في لندن بالتعاون مع مدرسة لندن الاقتصادياة. محرر

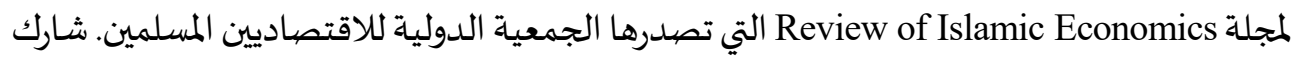
في تأسيس معهد ماركفيلد للدراسات العليا (MIHE) بمدينة ليستر بالمملكة المتحدة بالتنسيق مع الجامعات البريطانية التي منحت اعتمادها العلمي للمعهد خلال الفترة المذكورة (جامعات بورتسوث، لافبره وجلوسترشير) متوليًا عملية تخطيط وإدارة قسم الدراسات المصرفية الإسلامية والتمويلية

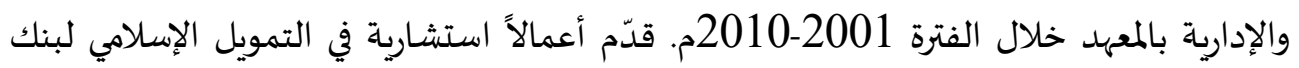
دويتش العالمي في لندن Bank Deutsche، وأعمالاً تدربية للبنك الإسلامي البريطاني خلال فترة

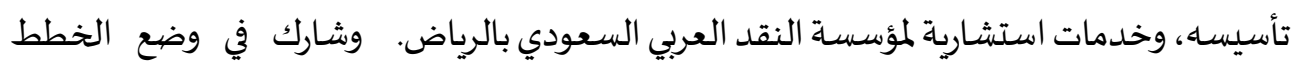

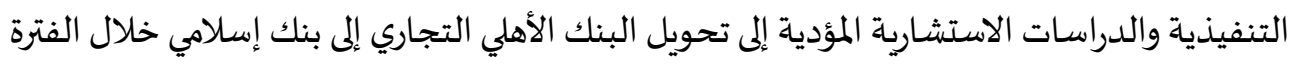
1992-1999م بما في ذلك تدريب كوادر البنك الأهلي والمساهمة في هيكلة الصناديق الاستثمارية

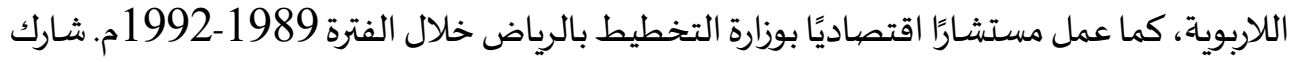

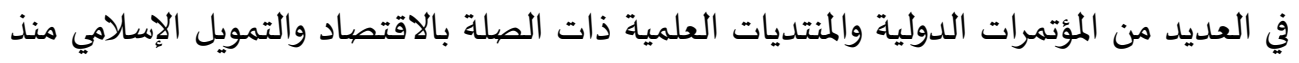

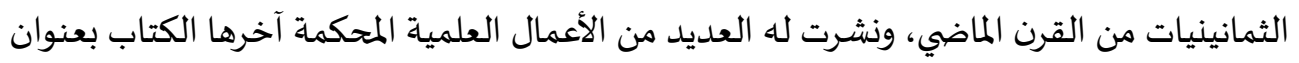
المتحة Maqasid Foundations of Market Economics المتحدة April 2013 البريد الإلكتروني الخاص للمؤلف: s.i.tageldin@gmail.com 


\title{
Market Competitiveness and Anti-monopolist Policy: Lesson Learned from Riba Al-Fadl Prohibition
}

\author{
Seif el-Din Ibrahim Tag el-Din \\ College of Economics and Social Sciences \\ Imam Muhammad bin Saud Islamic University, Riyadh
}

\begin{abstract}
The objective of this paper is to discuss and assess some hypotheses purporting to explain the economic damage associated with riba al-fadhl through the methodology of Islamic economics that depends on the derivation of Shariah objectives and translating them into strategic policies for modern Muslim societies - even though it utilizes concepts and tools of neoclassical economics. The paper justifies the anti-monopoly hypothesis and protection of competitiveness by reference to the Maliki reasoning that attaches the property of staple-storable food to the four ribawi items (dates, wheat, barley, salt), given the fact that staple storable food would normally command strong market demand and low priceelasticity. Then to analytically confirm that hypothesis against alternative ones suggested by earlier scholars (Ghaban prevention, blocking of means to riba alnasaa' and dropping luxurious purpose), a suitable analytical framework with reasonable assumptions has been introduced. In particular, ghaban-possibilities model has been developed to assess the three alternative hypotheses while qualitydifferential equilibrium model has been used to assess the anti-monopoly hypothesis. The end result seems to support the anti-monopoly hypotheses while offering no theoretical support to any of the three alternative hypotheses.
\end{abstract}

KEYWORDS: Riba Al-Fadl, hoarding prevention, competitiveness efficiency, economic analysis, Maqasid methodology.

JEL CLASSIFICATION: A11, A12, B410, B590

KAUJIE CLASSIFICATION: B2, B5, C3, H22, I11, I16 